\title{
A qualidade visual da paisagem do Parque Estadual da Ilha Anchieta, Ubatuba (SP)
}

\section{Quality visual landscape of State Park Anchieta Island, Ubatuba (SP, Brazil)}

\author{
Leonardo Silva Junior, Jéssica Andrade Vilas Boas, \\ Marcos Eduardo Cordeiro Bernardes, Maria Inês Nogueira Alvarenga
}

\section{RESUMO}

Os processos ecológicos contribuem de forma ímpar para a sobrevivência humana, pois são capazes de fornecer condições essenciais à manutenção da vida na Terra, além de permitir que ecossistemas se mantenham em equilíbrio. Nesse cenário, algumas áreas designadas legalmente pelo poder público visam à proteção em relação às ações antrópicas. Mesmo assim, estas áreas protegidas vêm sofrendo continuamente pressões humanas. O Parque Estadual da llha Anchieta (PEIA), localizado no litoral norte do estado de São Paulo, é uma das áreas protegidas mais visitadas desse estado. Diversas atividades recreativas são permitidas em seu interior, possibilitando assim possíveis impactos negativos aos processos ecológicos. O objetivo deste trabalho foi avaliar a qualidade visual da paisagem do PEIA, por meio de indicadores ambientais. Foram selecionadas 10 paisagens de alta relevância quanto a sua beleza cênica, fluxo de turistas, amplitude visual, relevância educacional e grau de conservação ambiental. As paisagens encontram-se em diferentes altitudes, fitofisionomias, aspectos abióticos e níveis de acesso público, o que confere diversidade espacial e características únicas a elas. Os seguintes indicadores visuais foram usados na classificação das paisagens: diversidade; naturalidade; singularidade e detratores. Além disso, os locais foram georreferenciados e fotografados. Como resultado, quatro locais apresentaram qualidade visual média; quatro, com qualidade visual média superior e duas paisagens com qualidade visual superior. Em geral, a qualidade visual foi inferior nas zonas onde o acesso aos turistas é facilitado por trilhas e infraestrutura de apoio. Já regiões mais afastadas e de difícil acesso foram as que apresentaram melhor qualidade visual. Deste modo, conclui-se que de fato a interferência humana reflete diretamente na qualidade visual das paisagens. Portanto, medidas de gestão ambiental, principalmente a atualização e efetiva implementação do seu plano de manejo, que data de 1989, podem dar suporte a uma proteção mais qualificada ao parque, bem como proporcionar uma experiência ainda mais agradável e educativa aos seus visitantes.

PALAVRAS-CHAVE: Ecoturismo; Áreas Protegidas; Indicadores Ambientais. 


\section{ABSTRACT}

Ecological processes contribute in a unique way to human survival, as they provide essential conditions for sustaining life on Earth and support equilibrium conditions. In this scenario, some areas legally designated by public policies are planned to protect natural from anthropogenic action. Even though, these protected areas have continuously been suffering human pressure. The State Park of Anchieta Island (PEIA), located on the northern coast of São Paulo, is one of the most visited protected areas of this state. Several recreational activities are allowed within the park, thus enabling possible negative impacts on ecological processes. This study aimed to assess the visual quality of PEIA landscape through environmental indicators. Ten landscapes of high relevance were selected, based on their scenic beauty, tourist flow, visual range, educational relevance and environmental conservation level. These landscapes present different altitudes, vegetation types, abiotic aspects and public access levels, which ensure spatial diversity and unique characteristics to them. The following visual indicators were used in the classification of landscapes: diversity; naturalness; uniqueness and detractors. Furthermore, the sites were geographically located and photographed. As a result, four sites presented medium visual quality; four, medium superior visual quality and two landscapes with superior visual quality. In general, the visual quality was lower on those zones where access to tourists is facilitated by trails and infrastructure support. On the other hand, more remote areas and those of difficult access were regarded as the best visual quality. It is concluded that in fact human interference directly reflects on the visual quality of the landscape. Thus environmental management measures, mainly updating and fully implementing its management plan, dating from 1989, can provide a more qualified protection to the park and also ensure an even more enjoyable and educational experience to its visitors.

KEYWORDS: Ecotourism; Protected Areas; Environmental Indicators.

\section{Introdução}

A conservação e preservação de ambientes naturais tem sido debatida com significativa intensidade nas últimas décadas, em função da elevada demanda da exploração de recursos naturais pela humanidade. Tal fato é considerado por muitos como premissas para o desenvolvimento econômico e urbano, contudo, ecossistemas naturais têm cada vez mais, perdido sua identidade original. Neste contexto as atividades exercidas pelo homem, promulgam debilidade na perpetuação da vida silvestre, na conservação das florestas, redução do fluxo gênico, diminuição da recarga de cursos d'água, alteração do clima e demais impactos que culminam na instabilidade das diversas formas de vida e seus ambientes na Terra.

Assim, a biodiversidade constitui papel importantíssimo na dinâmica ecológica dos recursos naturais, configurando-se como fator essencial para melhor promoção dos serviços ecossistêmicos e consequentemente à sustentabilidade nas dimensões econômicas e socioculturais (HECTOR; BAGCHI, 2007). As áreas protegidas desempenham papel singular na proteção e conservação da biodiversidade e dos recursos naturais, haja vista ainda, que ocupam aproximadamente $12 \%$ da superfície terrestre, entretanto, atualmente a gestão destas, não garantem a potencialização de seus benefícios, além de notoriamente 
a taxa de biodiversidade estar em redução alarmante (BUTCHART, et al., 2010; UNEP-WCMC, 2008; DAVEY, 1998).

De acordo com a International Union for Conservation of Nature (IUCN), as áreas protegidas devem imprescindivelmente conservar a composição, estrutura, função e potencial evolutivo da biodiversidade; contribuir para as estratégias regionais de conservação; manter a interação entre a biodiversidade e os ecossistemas; possuir um sistema gerencial transparente e equitativo, entre outros. Ainda segundo este autor, há seis categorias de áreas protegidas, sendo elas: Categoria la/lb (Estrita Reserva Natural/Área de Deserto); Categoria II (Parque Nacional); Categoria III (Monumento Natural ou Recurso); Categoria IV (Área de Gestão de Habitat/Espécie); Categoria V (Proteção à paisagem terrestre/marinha) e; Categoria VI (Área Protegida com Uso Sustentável de Recursos Naturais) (IUCN, 2013).

No Brasil, uma das diversas áreas protegidas existentes são denominadas de Unidades de Conservação (UC), constituintes de um sistema que contempla diversas espécies dentro de duas categorias: Proteção Integral, na qual objetivase, basicamente a preservação natural, com mínimas e/ou uso indireto dos recursos naturais, como os Parques Nacionais (PARNA), Reservas Biológicas (REBio), Estações Ecológicas (EE), Monumento Natural (MONA) e Refugio de Vida Silvestre (RVS); e a categoria de Uso Sustentável, admitindo-se, o uso dos bens naturais de forma sustentável e em consonância com a conservação do meio, tais como as Áreas de Proteção Ambiental (APA), Áreas de Relevante Interesse Ecológico (ARIE), Florestas Nacional (FLONA), Reservas Extrativistas (RESEX), Reservas de Fauna (REFAU), Reservas de Desenvolvimento Sustentável (RDS) e Reserva Particular do Patrimônio Natural (RPPN) (BRASIL, 2000).

Assim, tais áreas são regulamentadas pelo Sistema Nacional de Unidades de Conservação (SNUC), criado em 2000, por meio da Lei oㅜ 9.985. No entanto, a criação da primeira UC no Brasil não regularizou-se contemporaneamente à esta norma, pois em 1937, o Parque Nacional do Itatiaia, no Rio de Janeiro, tornara-se pioneiro na conservação de áreas naturais no país (ROCHA; DRUMMOND; GANEM, 2010). Desta forma, as UCs configuram territórios de exímia importância no território brasileiro, eficientes para garantir a preservação da biodiversidade e dos serviços ambientais fornecidos à sociedade (BRUNER, et al., 2001).

De acordo Prates (2012), o Brasil possui cerca 1.698 UCs geridas pelas esferas federal, estadual e municipal, além das particulares, representando uma área de aproximadamente 1,43 milhão de $\mathrm{km}^{2}$. E quanto à gestão destas áreas, no ano de 2007, a competência para criação, conservação e administração das UCs brasileiras foram incumbidas ao Instituto Chico Mendes de Conservação da Biodiversidade (ICMBio), porém os estados possuem autonomia para gerenciar suas próprias UCs, mesmo muitos ainda não tendo implementado nenhum sistema para geri-las (BERNARD; PENNA; ARAÚJO, 2014).

Neste contexto, o cerne da gestão das UCs conflita inúmeras adversidades, em relação ao uso e conservação dos recursos naturais em áreas legalmente protegidas, corroborando conflitos socioambientais entre ambientalistas e a população usuária, já que, em muitas destas, a população humana já se beneficiava dos bens ambientais, antes mesmo das implementações normativas (BUNSUSAN, 2006). Assim, Brockeman et al. (2002) acreditam que, principalmente as UCs de proteção integral como os parques, hão de vislumbrar de forma mais 
sistemática, um desencadeamento da utilização sustentável da população nessas áreas, como o próprio ecoturismo, buscando formas de preservação do patrimônio natural.

\section{Unidades de conservação e o uso antrópico}

O artigo $2^{\circ}$ da Lei $n^{\circ}$ 9.985, de julho de 2000, define Unidades de Conservação (UCs) como sendo áreas geográficas destinadas à preservação dos ecossistemas naturais, com limites definidos e sob um regime especial de administração, ao qual se aplicam garantias adequadas de proteção. É a principal proposta para diminuir os efeitos de degradação de ecossistemas no Brasil (BRASIL, 2000). A criação desses espaços legalmente protegidos é vista como uma importante estratégia de controle do território, uma vez que estabelece limites e dinâmicas de uso e ocupação.

O controle e os critérios de uso aplicados nas UCs são atribuídos em função da valorização dos recursos naturais existentes nas localidades, ou pela necessidade de proteger biomas, ecossistemas e espécies raras ou ameaçadas de extinção (MEDEIROS, 2006). De acordo com Gurgel, Ferreira e Luiz (2003), no interior das UCs, a partir do zoneamento da área e respeitadas as características sociais e ambientais, é permitido realizar atividades que fomentam 0 desenvolvimento social, econômico e científico, tanto local quanto nacional. Logo, o que se busca com a criação dessas áreas é uma complementaridade entre conservação da natureza e desenvolvimento sustentável.

Uma das espécies de UCs inseridas dentro da categoria de proteção integral e que permitem a interação homem e natureza, os parques estaduais, surgiram no Sul e no Sudeste do Brasil (Minas Gerais, São Paulo, Rio de Janeiro e Rio Grande do Sul), nos anos 1930 e 1940. Atualmente, em São Paulo e em Minas Gerais, por exemplo, estão o maior número de unidades de conservação, apesar de não representarem a maior extensão territorial, que se encontra na Amazônia. São destinadas a preservar áreas naturais, abrangendo paisagens, ecossistemas e/ou sítios geológicos de grande interesse para atividades científicas, educacionais, recreativas e de lazer, realizadas em obediência aos Planos de Manejo. Neste sentido, o aumento de impactos causados pela visitação através do ecoturismo deve ser gerenciado de modo a não afetar a conservação dos ambientes naturais.

O MCIT/MMA (1994), define o ecoturismo como uma modalidade turística, sendo considerado um segmento da atividade turística que utiliza de forma sustentável o patrimônio natural e cultural, incentivando sua conservação e conscientização, através da interpretação do ambiente promovendo o bem-estar das populações. Por outro lado, com o aumento da frequência de pessoas na costa brasileira em virtude das atividades turísticas, passa-se a ter uma maior necessidade de planejamento do uso do solo e gestão desses espaços. Além disso, torna-se vital a determinação e o monitoramento dos impactos produzidos pela prática do ecoturismo. Notoriamente, há sazonalmente um crescimento exponencial da economia local e, paralelamente essa convergência populacional resulta em impactos ambientais negativos (ALMEIDA, 2000).

Assim, o meio biótico e abiótico são reflexos nítidos dos impactos costeiros. De acordo com Brotto et al., (2012) o ecoturismo, vem acarretando desestabilização de ecossistemas marinhos, principalmente pela falta de conscientização e 
disposição incorreta de resíduos sólidos. Estas áreas protegidas acabam sendo utilizadas como refúgio do desconforto urbano pela sociedade, contrastando com seus princípios preservacionistas, tornando-se indiretamente áreas de constantes degradações ambientais como, incêndios, caça à animais silvestres, inserção de espécies invasoras e domésticas, deposição de resíduos, supressão de vegetação, dentre outros impactos (SOUZA, 2011). Nesse sentido, Cunha e Guerra (2005), mencionam que as agências de ecoturismos, deveriam além de prezar pela segurança, satisfação e bem-estar de seus clientes, prezar pela sustentabilidade tanto ambiental como sociocultural das atividades realizadas no local de visita.

Segundo Sartafi e Sano (2012), a gestão dos parques estaduais é o elemento chave para promoção do equilibro ecológico nesses ambientes, onde a falta de estruturação e inadequação administrativa acarretam em um turismo "negativo", causando resultados díspares em um local de extrema valorização ambiental. Oliveira (2011) cita a necessidade de maior valorização de ambientes naturais com tradições culturais e históricas, por meio das políticas estaduais, a fim de promover o ecoturismo consciente e o despertar conservacionista de cada cidadão usuário destes locais. Observa-se ainda que a sociedade como um todo espera mudanças nos procedimentos e normas de utilização de espaços naturais e preservados, com o intuito de equilibrar o turismo e a conservação ambiental (TOMANIK; NAKAGAWA, 2011).

Sendo assim, a capacitação dos principais atores envolvidos com a gestão do ecoturismo nos parques estaduais é uma das prioridades para o desenvolvimento socioambiental da região, contribuindo efetivamente para conservação das paisagens naturais, consequentemente gerando maior atratividade aos visitantes (KOGA; OLIVEIRA; KANESHIRO, 2013).

\section{O Parque Estadual da Ilha Anchieta: Turismo e preservação ambiental}

Localizado no litoral norte do estado de São Paulo, o PEIA, está a aproximadamente $7 \mathrm{~km}$ de distância da costa do município de Ubatuba. De acordo com IBGE (2015), a cidade comporta atualmente cerca de 85 mil habitantes em uma área de aproximadamente $723 \mathrm{~km}^{2}$. No passado, a Ilha Anchieta abrigou um centro de detenção de presos políticos de todo o país, como um presídio de segurança máxima, já que é circundado pelas águas do Atlântico. Contudo, após a rebelião em 1952, a então denominada Colônia Correcional do Porto das Palmas, deixou de ser presídio em 1955. Em 1977, foi instituído o parque estadual, sendo este, uma UC de proteção integral. Em 2006, por meio do Decreto Estadual no 51.453, o PEIA passou a ser administrado pela Fundação Florestal do Estado de São Paulo e, desde então, faz parte do Sistema Estadual de Floresta - Sieflor (GUILLAUMON, J.R. et al., 1989; BRASIL, 2000; SÃO PAULO, 2006).

Atualmente, o PEIA possui instalações administrativas e de recepção ao público visitante e pesquisadores, como: centro de visitantes, prédio administrativo, alojamentos, banheiros, quiosques, ruínas do presídio e demais edificações da época, duchas de água doce, capela do Bom Jesus, dentre outros. Desta maneira, aspectos culturais, históricos e naturais, fizeram com que o parque se tornasse a segunda UC mais visitada do estado de São Paulo, recebendo em média, cerca de 80 mil pessoas por ano, com alta concentração na estação de verão (PÓLIS, 2013). 
O plano de manejo do PEIA, foi elaborado em 1989, sendo este um dos primeiros a ser concebido para UCs do Brasil. Desde então, não foi atualizado e apresenta incompatibilidades em relação às melhores práticas atuais, principalmente para o uso público, como adequação para acessibilidade aos turistas que desembarcam no PEIA, maior disposição de lixeiras nas praias, adaptação da zona de uso intensivo em relação ao fluxo de turistas principalmente nas praias do Engenho e Sul, entre outros. De acordo com o plano de manejo, o PEIA foi divido em quatro zonas, que caracterizam o uso da UC (Figura 1).

De acordo com Brasil (2000), o zoneamento em UCs tem o objetivo de segmentar zonas ou setores conforme suas peculiaridades ambientais, a fim de incitar métodos de manejo adequados para cada zona, contribuindo para que todo o espaço constituinte da UC possa estar em harmonia. Assim, essa divisão proporciona uma melhor administração do parque no uso público, norteando quais ambientes podem ser utilizados com maior ou menor intensidade. De acordo com Kataoka (2004), o programa de uso público, instituído no plano de manejo do PEIA, apresenta dois subprogramas, que são: "Turismo e recreação" e "Educação formal e interpretação". O primeiro visa proporcionar o lazer sustentável e a percepção do impacto econômico do parque para a região. Já o segundo objetiva levar a importância natural da preservação do parque no contexto turístico, bem como estimular a educação ambiental por meio de pesquisas cientificas.

\section{CARACTERIZAÇÃO E ZONEAMENTO DO PEIA}

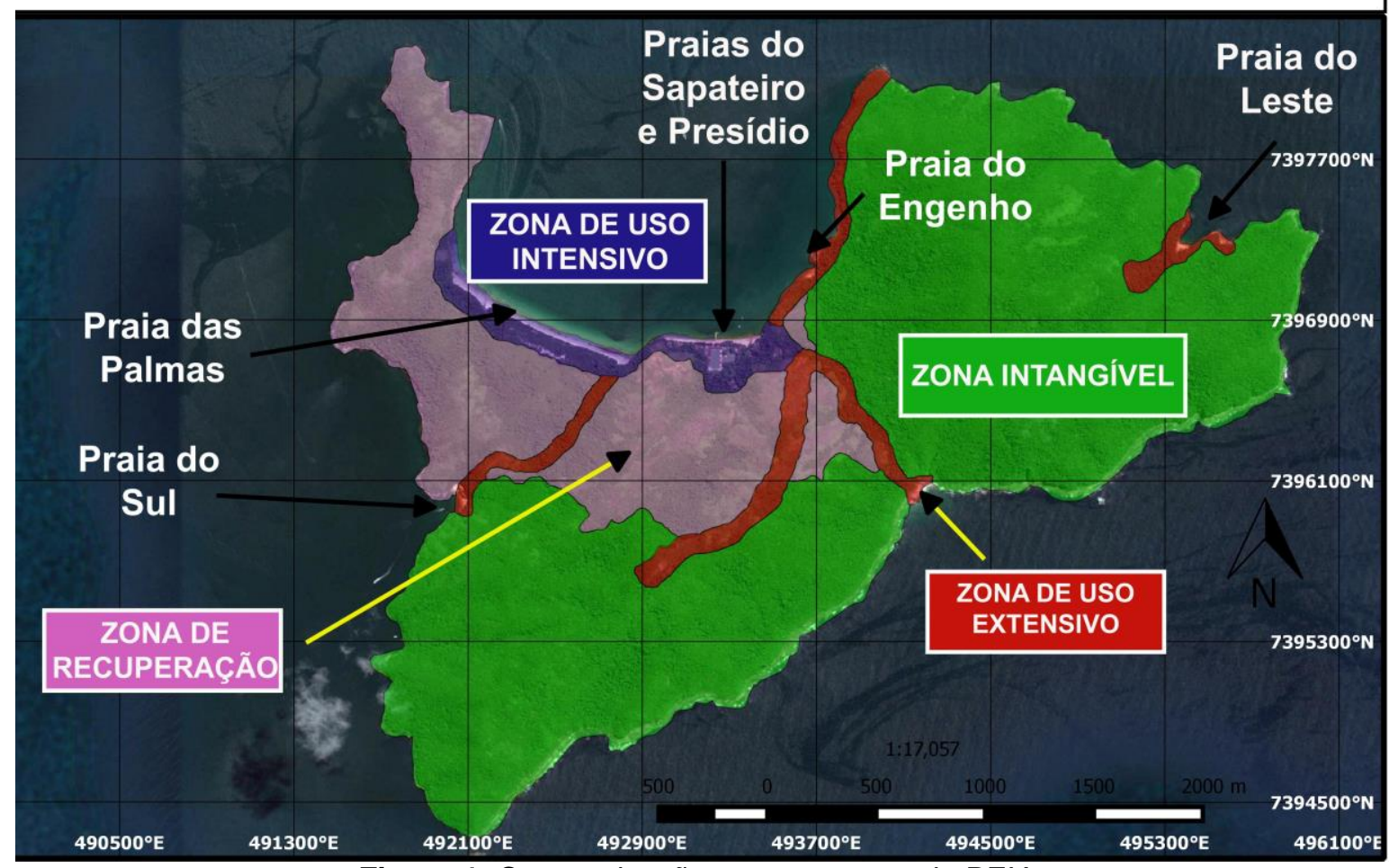

Figura 1: Caracterização e zoneamento do PEIA.

Fonte: Adaptado de Guillaumon et al. (1989) e Spelta (2011).

Figure 1: Characterization and zoning of PEIA.

Source: Adapted from Guillaumont et al. (1989) Spelt (2011). 
As zonas representadas são conceituadas da seguinte forma:

-Zona de uso intensivo - caracteriza a parte frontal do parque, local de recepção dos turistas, como o centro de visitantes, ruínas, praias do Presídio; do Sapateiro; do Engenho e das Palmas;

-Zona de uso extensivo - áreas que apresentam certas alterações humanas e são utilizadas para promover educação ambiental;

-Zona de recuperação - representam áreas que foram intensamente exploradas desde a época do presídio e hoje estão em processo de regeneração;

-Zona de uso intangível - caracteriza-se por apresentar melhor conservação, com ambientes naturais voltados principalmente à preservação e pesquisa cientifica (GUILLAUMON et al., 1989; SPELTA, 2011).

A zona de uso intensivo representa uma área com recursos ambientais em consonância às áreas alteradas pelo homem, como edificações e atividades de recreação intensiva. Já a zona de uso extensivo apresenta em sua grande parte áreas naturais com poucas alterações humanas, sendo esta destinada à acessos para o público e fins educativos e recreativo. Por fim, as zonas de recuperação e de uso intangível consistem similarmente na proibição de atividades humanas, diferindo-se significativamente no estado de conservação dos mesmos. A primeira trata-se de uma área que foi efetivamente antropizada e atualmente está à mercê da recuperação ecológica e a segunda consiste em uma área de natureza primitiva, representando alto grau de preservação (IBAMA, 2002).

Neste contexto de divisão de setores, o PEIA perante seu histórico social, foi e é fatidicamente utilizado de forma expressiva nas zonas intensiva, extensiva e de recuperação, devido à utilização destes espaços pelos turistas. Notadamente estes ambientes concernem alta passividade às atividades antrópicas e consequentemente configuram impactos nocivos ao ecossistema e paisagem natural. E desta forma, o objetivo desta pesquisa foi avaliar a qualidade visual da paisagem do PEIA por meio de indicadores ambientais.

\section{Materiais e métodos}

\section{Área de Estudo}

A pesquisa foi realizada entre os dias 6 e 24 de janeiro de 2015, no PEIA, localizado no município de Ubatuba, litoral norte do estado de São Paulo (Figura 2) - A escolha desse local se deu por ser uma unidade de conservação de proteção integral, possibilitado a presença de turistas, pesquisas científicas e educação ambiental, objetivando proteger a biodiversidade e preservar os ecossistemas naturais, bem como suas belezas cênicas (BRASIL, 2000). 


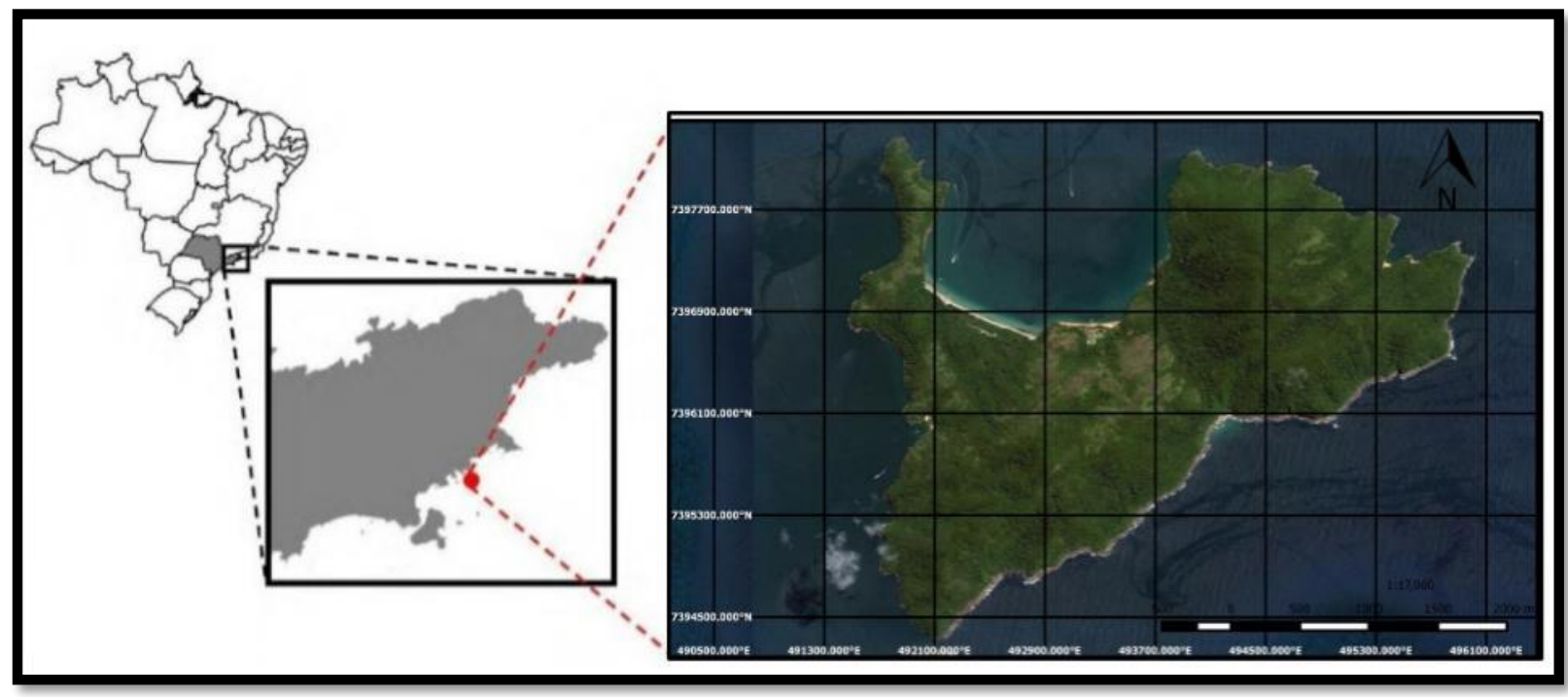

Figura 2: Localização do PEIA.

Fonte: Adaptado de Esteves (2010). Coordenadas UTM, Datum Córrego Alegre, zona 23 S.

Figure 2: Localization of PEIA. Source:

Source: Adapted from Esteves (2010). UTM coordinates, Datum Córrego Alegre, zone 23 S

O PEIA caracteriza-se por ser uma ilha, estando a aproximadamente $7 \mathrm{~km}$ de distância do ponto mais próximo ao continente. Apresenta 828 hectares, com altitude máxima de aproximadamente $350 \mathrm{~m}$ e possui clima tropical úmido e ecossistemas marinho e terrestre, sendo este último constituído pelo bioma de Mata Atlântica, representado pela floresta ombrófila densa, restinga e vegetação de costão rochoso (KATAOKA, et al., 2011).

\section{Metodologia}

A pesquisa se deu de forma aplicada, buscando-se novos conhecimentos, a fim de, solucionar determinados problemas, qualitativa, utilizando-se da subjetividade e uma abordagem descritiva e de campo, realizando-se procedimentos de coleta de dados em locais onde ocorram fenômenos de interesse (GIL, 2008; KAUARK; MANHÃES; MEDEIROS, 2010; SOUZA, et al., 2013; VERGARA, 2000). Assim, o trabalho foi adaptado ao de Pires (2005) e de Soares, Medeiros e Sales Filho (2014), na qual buscou-se avaliar a qualidade visual da região exposta a atividades turísticas por meio de indicadores ambientais.

Contudo, a percepção da paisagem é considerada um ato criativo de personalidade influenciada por aspectos socioculturais (FONT, 1992). De acordo com Machado (1997), a qualidade ambiental está inteiramente ligada à qualidade de vida, ou seja, vida e ambiente estão interligados, havendo interação e equilíbrio entre ambos. A subjetividade está inserida nas atribuições que cada indivíduo fornece ao meio. Sendo assim, foi realizada uma análise conjunta de opiniões de uma mesma paisagem, entre os pesquisadores, classificando a mesma coletivamente. Deste modo, o procedimento metodológico se deu a partir da escolha de dez pontos de significância ambiental na paisagem, como mirantes, vistas panorâmicas, locais de atrativos turísticos e de potencial concentração de recursos naturais (Figura 3 ). 


\section{CARACTERIZAÇÃO E LOCALIZAÇÃO DAS PAISAGENS}

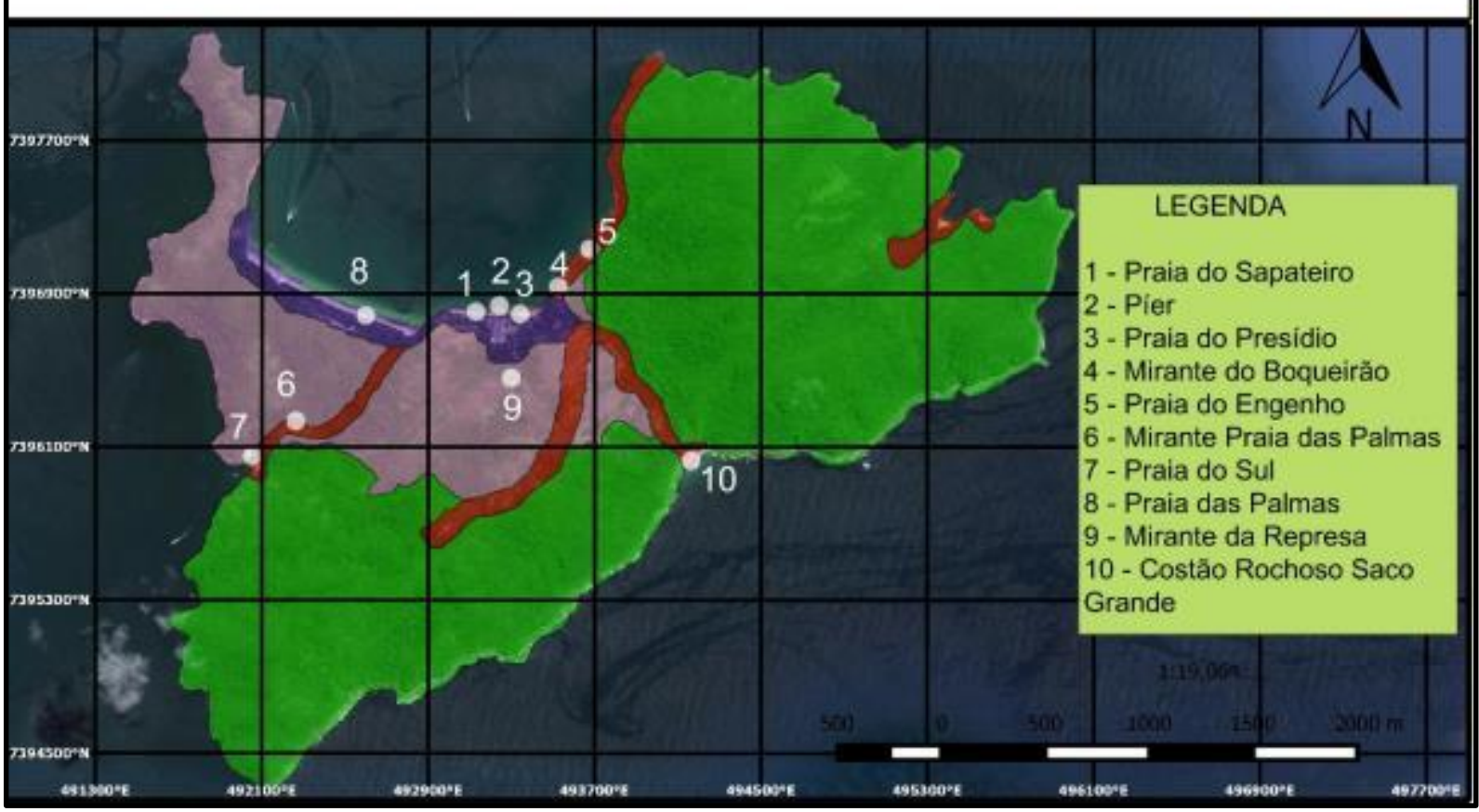

Figura 3: Caracterização por zoneamento e localização dos pontos amostrados. Fonte: Autores (2015) Figure 3: Characterization by zoning and location of sampling sites. Source: Authors (2015).

As paisagens selecionadas foram georreferenciadas por meio de GPS da marca Garmin, modelo ETrex 30. Em cada paisagem, foi feito um registro fotográfico com uma câmera HD semiprofissional da marca Sony, modelo DSC-HX $100 \mathrm{~V}$, posicionada sobre um tripé, na altura de 1,20 $\mathrm{m}$. Os registros das cenas observadas foram realizados por fotos panorâmicas, perfazendo um giro sequencial sobre o eixo horizontal de forma a compor um mosaico contínuo, podendo chegar a 180 de angulação, sem utilização do zoom.

Posteriormente, por meio de uma ficha de campo, foi feita a coleta de dados que permitiu a análise da qualidade da paisagem, a fim de se classificar cada cena observada. Primeiramente, foram coletadas informações de relevância para classificar as paisagens, tais como: identificação; cena observada; coordenadas geográficas e altitude. Em cada local, foram caracterizados os principais componentes do meio observados. Para classificação do meio, foram utilizados os seguintes indicadores visuais:

Diversidade: expressa a variedade paisagística do meio. Quanto maior a diversidade, maior valor é atribuído neste indicador (Quadro 1). 
Quadro 1: Descrição do indicador de diversidade visual.

Frame 1: Description of visual diversity indicator.

\begin{tabular}{|c|c|c|c|c|c|}
\hline \multicolumn{6}{|c|}{ DIVERSIDADE VISUAL } \\
\hline \multirow{2}{*}{ componentes } & \multirow{2}{*}{$\begin{array}{l}\text { Propriedades } \\
\text { visuais }\end{array}$} & \multicolumn{4}{|c|}{ nível de destaque } \\
\hline & & grande (6) & moderado (3) & pouco (1) & nenhum (0) \\
\hline \multirow{2}{*}{ Relevo } & forma/volume & & & & \\
\hline & linha & & & & \\
\hline \multirow{3}{*}{ Vegetação } & textura & & & & \\
\hline & cor/tonalidade & & & & \\
\hline & forma & & & & \\
\hline \multirow{2}{*}{ Água } & cor/tonalidade & & & & \\
\hline & linha/forma & & & & \\
\hline \multirow{3}{*}{$\begin{array}{l}\text { Atividades } \\
\text { Humanas }\end{array}$} & forma & & & & \\
\hline & cor & & & & \\
\hline & linha & & & & \\
\hline \multicolumn{2}{|c|}{ total: } & & & & \\
\hline \multirow{3}{*}{$\begin{array}{c}\text { ESCALA DE } \\
\text { CLASSIFICAÇÃO }\end{array}$} & \multicolumn{3}{|c|}{31 - 60: Alta diversidade (AD) } & \multirow{2}{*}{\multicolumn{2}{|c|}{ CLASSIFICAÇÃO: }} \\
\hline & \multicolumn{3}{|c|}{11 - 30: Média diversidade (MD) } & & \\
\hline & \multicolumn{3}{|c|}{ Até 10: baixa diversidade (BD) } & & \\
\hline
\end{tabular}

Fonte: Adaptado de Pires (2005). Source: Adapted from Pires (2005).

As variáveis do indicador "Diversidade visual" foram conceituadas da seguinte maneira:

-Forma/volume - volume ou superfície dos componenentes do meio que se apresentam sobre a linha do terreno, configurando a paisagem;

-Linha - contorno ou delimitações dos componentes do meio;

- Textura - agregação de formas e cores identificadas como variações ou irregularidades no meio observado;

-Cor/tonalidade - representação das diferentes cores observadas no meio.

Assim, cada variável recebeu um nível de destaque (nota em escala de zero a seis) e, ao final, quando somadas, pôde-se enquadrar o resultado em alta diversidade (AD), média diversidade (MD) ou baixa diversidade (BD).

Naturalidade: representa o quanto o meio está isento ou distante de ações humanas, como edificações e alterações do meio. Quanto menos ações antrópicas, maior a interação entre o meio biótico e o físico, indicando um ambiente com maior naturalidade (Quadro 2). 
Quadro 2: Naturalidade.

Frame 2: Naturalness.

\begin{tabular}{|l|c|}
\hline \multicolumn{1}{|c|}{ NATURALIDADE } \\
\hline \multicolumn{1}{|c|}{ Gradiente de modificação da paisagem } & Classificação \\
\hline $\begin{array}{l}\text { Paisagem natural sem alterações visíveis } \\
\text { Paisagem natural pouco alterada }\end{array}$ & Naturalidade Superior (S) \\
\hline $\begin{array}{l}\text { Paisagem predominantemente natural com alterações } \\
\text { pequenas a moderadas }\end{array}$ & $\begin{array}{c}\text { Naturalidade Média- } \\
\text { Superior (MS) }\end{array}$ \\
\hline $\begin{array}{l}\text { Paisagem tipicamente rural (campestre, cultivada, colonial) } \\
\text { Paisagem urbana/Peri-urbana com entorno predominantemente } \\
\text { natural }\end{array}$ & $\begin{array}{c}\text { Naturalidade Média-Inferior } \\
\text { (MI) }\end{array}$ \\
\hline $\begin{array}{l}\text { Paisagem peri-urbana misturada com elementos da paisagem } \\
\text { rural. } \\
\text { Paisagem urbana/peri-urbana com presença de elementos } \\
\text { naturais em seu entorno } \\
\text { Paisagem urbana com expressiva presença de áreas verdes. }\end{array}$ & Naturalidade Inferior (NI) \\
\hline \multicolumn{2}{|c|}{ Classificação: }
\end{tabular}

Fonte: Adaptado de Pires (2005). Source: Adapted from Pires (2005).

Cada variável correspondeu a um gradiente de modificação da paisagem: desde aquela totalmente natural a uma paisagem urbanizada com presença de áreas verdes. Ao se verificar a cena observada, buscou-se identificar na paisagem a presença de ações antrópicas, podendo assim se inferir o quão natural encontrase o meio.

Singularidade: reflete a importância de determinado atributo do meio, como raridades, espécies endêmicas, paisagem de excepcional beleza, ocorrência de fenômenos atmosféricos como nascer ou pôr do sol, arco-íris, ocorrência de interesse histórico ou cultural que possua expressão visual, sítio arqueológico, área de importância ecológica ou educativa, entre outros (Quadro 3). 
Quadro 3: Singularidade.

Frame 3: Singularity.

\section{SINGULARIDADE}

Critérios de identificação

Nota $(0$ - 10)

Presença na paisagem de componentes e/ou suas propriedades visuais com

atributos tais como unicidade, raridade, grandiosidade, excepcional beleza

Grande amplitude visual

(paisagem extremamente panorâmica)

Ocorrência de fenômenos atmosféricos notáveis tais como nascer e pôr do sol, arco-íris, nuvens e nebulosidade, neve, geada

Presença de fauna

Paisagem natural sem alterações

Presença na paisagem de ocorrências ou aspectos ecológicos, geográficos ou

ambientais de relevância educativa ou científica

Ocorrência de interesse histórico ou cultural que possua expressão visual

Total

\section{Critérios de classificação}

Ausência de singularidade (AS) 0

Limitado potencial de atratividade turística em nível sub-estadual (regional) (LSR)

De $1-3,33$

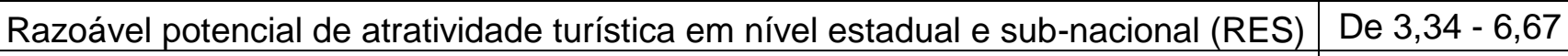

Grande potencial de atratividade turística em nível nacional e internacional (GNI) De 6, 68 - 10

Classificação:

Fonte: Adaptado de Pires (2005). Source: Adapted from Pires (2005).

Foram listados os critérios de identificação (variáveis), buscando-se atribuir a cada variável uma nota de 0 a 10, de acordo com o observado nas paisagens. Peculiarmente neste indicador, por abster-se de variáveis que modificam-se espaço-temporalmente, como fenômenos atmosféricos e presença de fauna, aplicou-se o método normalmente, atribuindo as notas pelos pesquisadores em cada variável, de acordo com sua interpretação visual, chegando à um consenso final. No entanto, utilizou-se também de, entrevistas aos funcionários e gestores do PEIA, para diagnosticar quais variáveis destas acima, frequentemente estão presentes nas paisagens selecionadas. Ao final das atribuições, com o resultado do somatório das notas de cada critério de identificação pôde-se então, enquadrar a paisagem nos critérios definidos por Pires (2005), que conceitua a paisagem em relação ao potencial de atratividade turística aos níveis subestadual, estadual, subnacional, nacional e internacional.

Detratores: representam o quão impactante está a paisagem observada, por meio de artificializações, edificações e ações antrópicas como um todo (Quadro 4). 


Quadro 4: Detratores.
Frame 4: Detractors
\begin{tabular}{|c|c|}
\hline \multicolumn{1}{|c|}{ DETRATORES } \\
\hline Critérios de classificação & sigla \\
\hline Ausência de detrator & ADe \\
\hline Pequeno detrator & PDe \\
\hline Conjunto de pequenos detratores & MDe \\
\hline Médio detrator & Cj-MDe \\
\hline Conjunto de médios detratores & GDe \\
\hline Grande detrator & Cj-GDe \\
\hline Conjunto de grandes detratores & \\
\hline \multicolumn{2}{|c|}{ Classificação: } \\
\hline
\end{tabular}

Fonte: Adaptado de Pires (2005). Source: Adapted from Pires (2005).

Após análise dos indicadores em campo, transferiu-se cada resultado (sigla) de seu respectivo indicador para o quadro de avaliação final da qualidade visual da paisagem. Assim, foi obtida uma classificação geral dos resultados (siglas) dos indicadores (Quadro 5).

Quadro 5: Avaliação final da qualidade da paisagem.

Frame 5: Final evaluation of landscape quality.

\begin{tabular}{|c|c|}
\hline \multicolumn{2}{|c|}{ AVALIAÇÃO FINAL DA QUALIDADE VISUAL DA PAISAGEM } \\
\hline Classe de qualidade visual & Parâmetros de enquadramento \\
\hline Qualidade visual superior (S) & AD / S / GNI / ADe / PDe \\
\hline Qualidade visual médio-superior (MS) & MD / MS / RES / PDe / Cj-Pde \\
\hline Qualidade visual média (M) & $\mathrm{MD} / \mathrm{MS} / \mathrm{MI} / \mathrm{RES} / \mathrm{LSR} / \mathrm{MDe} / \mathrm{Cj}-\mathrm{MDe}$ \\
\hline Qualidade visual média inferior (MI) & $\mathrm{MD} / \mathrm{Ml} / \mathrm{LSR} / \mathrm{Cj}$-MDe / GDe \\
\hline Qualidade visual inferior & $\mathrm{BD} / \mathrm{NI} / \mathrm{AS} / \mathrm{GDe} / \mathrm{Cj}$-GDe \\
\hline \multicolumn{2}{|c}{ Classificação: } \\
\hline
\end{tabular}

Fonte: Adaptado de Pires (2005). Source: Adapted from Pires (2005).

Para se classificar as paisagens, verificou-se 0 parâmetro de enquadramento que apresentou maior número de resultados (siglas). Ou seja, uma paisagem é classificada a partir da combinação entre as quatro variáveis (siglas) obtidas de acordo com os resultados de cada indicador. Por exemplo, para a classificação "AD/MS/RES/Cj-MDe", considerou-se que a variável AD está presente 
apenas na "qualidade visual superior (S)". As variáveis MS e RES estão presentes em duas das classes de qualidade visual, porém a variável Cj-MDe está presente apenas na "qualidade visual média (M)", classificando assim, a paisagem como qualidade visual média. Portanto, o parâmetro de enquadramento que apresentou mais siglas correspondeu à classe de qualidade visual, que varia desde qualidade visual inferior até qualidade visual superior. Classificou-se assim a qualidade visual da paisagem, como está representado no Quadro 5.

\section{Resultados e discussão}

\section{Diagnóstico das paisagens}

Após análise dos dados obtidos em campo, pôde-se elaborar um panorama da qualidade visual das paisagens no PEIA. Os quadros 6 e 7 mostram a análise da qualidade visual das paisagens e caracterização e classificação das mesmas respectivamente.

Quadro 6: Descrição dos resultados por indicador.

Frame 6: Description of the results by indicator.

\begin{tabular}{|c|c|c|c|c|c|c|}
\hline \multicolumn{7}{|c|}{ ANÁLISE DA QUALIDADE VISUAL DA PAISAGEM } \\
\hline PONTO & LOCAL & DIVER. & NATUR. & SING. & DETR. & CLAS. \\
\hline 1 & Praia do Sapateiro & AD & MS & RES & Cj-Mde & M \\
\hline 2 & Píer & AD & MS & RES & Gde & M \\
\hline 3 & Praia do Presídio & AD & MS & RES & Cj-Mde & M \\
\hline 4 & Mirante do Boqueirão & MD & S & RES & PDe & MS \\
\hline 5 & Praia do Engenho & MD & S & RES & Cj-Pde & MS \\
\hline 6 & Mirante das Palmas & MD & S & RES & PDe & S \\
\hline 7 & Praia do Sul & MD & S & RES & PDe & MS \\
\hline 8 & Praia das Palmas & AD & S & RES & PDe & S \\
\hline 9 & Mirante da Represa & MD & MS & RES & MDe & M \\
\hline 10 & Costão Rochoso do Saco & MD & S & RES & PDe & MS \\
\hline
\end{tabular}

Onde:

Fonte: Autores (2015). Source: Authors (2015).

RES........Razoável potencial de atratividade turística em nível estadual e sub-nacional

AD.......... Alta Diversidade

MD...........Média Diversidade

MS ..........Naturalidade Média-Superior

S.............Naturalidade Superior

Cj-MDe...Conjunto de Médio Detratores

GDe........Grandes Detratores

S.............Qualidade Superior

Cj-PDe....Conjunto de Pequenos Detratores

M.............Qualidade Média

MS...........Qualidade Média-Superior

Cj-PDe....Conjunto de Pequenos Detratores

PDe..........Pequenos Detratores

MDe.........Médios Detratores 
Quadro 7: Panorama das paisagens.

Frame 7: Panorama of landscapes

\begin{tabular}{|c|c|c|c|c|c|}
\hline \multicolumn{6}{|c|}{ CARACTERIZAÇÃO E CLASSIFICAÇÃO DA PAISAGEM } \\
\hline Ponto & Local & Coord./Altitude & $\begin{array}{c}\text { Componentes da } \\
\text { paisagem }\end{array}$ & Zoneamento & $\begin{array}{l}\text { Qualidade } \\
\text { visual }\end{array}$ \\
\hline 1 & Praia do Sapateiro & $\begin{array}{c}\text { Lat: S } 23^{\circ} 32^{\prime} 20,5^{\prime \prime} \\
\text { Long: } 045^{\circ} 04^{\prime} 02,4^{\prime \prime} \\
\text { Altitude: } 2 \mathrm{~m}\end{array}$ & $\begin{array}{l}\text { mar, píer, alojamentos, } \\
\text { área de lazer, } \\
\text { embarcações e sede } \\
\text { administrativa }\end{array}$ & $\begin{array}{l}\text { Zona de uso } \\
\text { Intensivo }\end{array}$ & $\begin{array}{l}\text { Qualidade } \\
\text { visual Média }\end{array}$ \\
\hline 2 & Píer & $\begin{array}{c}\text { Lat: S } 23^{\circ} 32^{\prime} 19,5^{\prime \prime} \\
\text { Long: O 45 } 03^{\prime} 58,4^{\prime \prime} \\
\text { Altitude: } 0 \mathrm{~m}\end{array}$ & $\begin{array}{c}\text { mar, píer, sede } \\
\text { administrativa, museu, } \\
\text { alojamentos, restinga, } \\
\text { embarcações, praias do } \\
\text { Sapateiro e Presídio }\end{array}$ & $\begin{array}{l}\text { Zona de uso } \\
\text { Intensivo }\end{array}$ & $\begin{array}{c}\text { Qualidade } \\
\text { visual Média }\end{array}$ \\
\hline 3 & Praia do Presídio & $\begin{array}{c}\text { Lat:S } 23^{\circ} 32^{\prime} 20.9^{\prime \prime} \\
\text { Long: } 0 \text { 45 } 03^{\prime} 54.9^{\prime \prime} \\
\text { Altitude: } 0 \mathrm{~m}\end{array}$ & $\begin{array}{c}\text { mar, píer, restinga, } \\
\text { embarcações, museu, } \\
\text { área de lazer, curso } \\
\text { d'água e sede } \\
\text { administrativa }\end{array}$ & $\begin{array}{l}\text { Zona de uso } \\
\text { Intensivo }\end{array}$ & $\begin{array}{c}\text { Qualidade } \\
\text { visual Média }\end{array}$ \\
\hline 4 & $\begin{array}{l}\text { Mirante do } \\
\text { Boqueirão }\end{array}$ & $\begin{array}{c}\text { Lat: S } 23^{\circ} 32^{\prime} 16.3^{\prime \prime} \\
\text { Long: O } 45^{\circ} 03^{\prime} 48.04 " \\
\text { Altitude: } 23 \mathrm{~m}\end{array}$ & $\begin{array}{c}\text { boqueirão, mar, } \\
\text { encostas, montanhas, } \\
\text { praias das Palmas e } \\
\text { Sapateiro e vegetação } \\
\text { de encosta }\end{array}$ & $\begin{array}{l}\text { Zona de uso } \\
\text { Extensivo }\end{array}$ & $\begin{array}{l}\text { Qualidade } \\
\text { visual médio- } \\
\text { superior }\end{array}$ \\
\hline 5 & Praia do Engenho & $\begin{array}{c}\text { Lat: S 230 32'09.8” } \\
\text { Long: O 45 03' 43.1" } \\
\text { Altitude: } 5 \mathrm{~m}\end{array}$ & $\begin{array}{c}\text { mar, embarcação, } \\
\text { costão rochoso, } \\
\text { encosta, montanhas, } \\
\text { curso d'água, piscina } \\
\text { natural, praia das } \\
\text { Palmas e ducha natural }\end{array}$ & $\begin{array}{l}\text { Zona de uso } \\
\text { Extensivo }\end{array}$ & $\begin{array}{l}\text { Qualidade } \\
\text { visual médio- } \\
\text { superior }\end{array}$ \\
\hline 6 & $\begin{array}{l}\text { Mirante praia das } \\
\text { Palmas }\end{array}$ & $\begin{array}{c}\text { Lat: S } 23^{\circ} 32^{\prime} 39.1^{\prime \prime} \\
\text { Long: O 45 } 04^{\prime} 32.9^{\prime \prime} \\
\text { Altitude: } 58 \mathrm{~m}\end{array}$ & $\begin{array}{c}\text { mar, vegetação de } \\
\text { encosta, restinga, } \\
\text { encostas, embarcações } \\
\text { e costa continental }\end{array}$ & $\begin{array}{l}\text { Zona de uso } \\
\text { Extensivo }\end{array}$ & $\begin{array}{l}\text { Qualidade } \\
\text { visual } \\
\text { superior }\end{array}$ \\
\hline 7 & Praia do Sul & $\begin{array}{c}\text { Lat: S } 23^{\circ} 32^{\prime} 45^{\prime \prime} \\
\text { Long: } \mathrm{O} 45^{\circ} 04^{\prime} 40.4^{\prime \prime} \\
\text { Altitude: } 1 \mathrm{~m}\end{array}$ & $\begin{array}{c}\text { mar, costão rochoso, } \\
\text { embarcações, } \\
\text { vegetação de encosta, } \\
\text { edificação abandonada } \\
\text { e curso d'água }\end{array}$ & $\begin{array}{l}\text { Zona de uso } \\
\text { Extensivo }\end{array}$ & $\begin{array}{l}\text { Qualidade } \\
\text { visual médio- } \\
\text { superior }\end{array}$ \\
\hline 8 & Praia das Palmas & $\begin{array}{l}\text { Lat: S } 23^{\circ} 32^{\prime} 21.1^{\prime \prime} \\
\text { Long: } 045^{\circ} 04^{\prime} 21^{\prime \prime} \\
\text { Altitude: } 1 \mathrm{~m}\end{array}$ & $\begin{array}{l}\text { mar, encosta, } \\
\text { embarcações, costão } \\
\text { rochoso, restinga e } \\
\text { costa continental }\end{array}$ & $\begin{array}{l}\text { Zona de uso } \\
\text { Intensivo }\end{array}$ & $\begin{array}{l}\text { Qualidade } \\
\text { visual } \\
\text { superior }\end{array}$ \\
\hline 9 & Mirante da Represa & $\begin{array}{c}\text { Lat: S } 23^{\circ} 32^{\prime} 21,7^{\prime \prime} \\
\text { Long: O 45 04' 20,9" } \\
\text { Altitude: } 73 \mathrm{~m}\end{array}$ & $\begin{array}{l}\text { mar, encosta, presídio, } \\
\text { embarcações, vista } \\
\text { parcial da sede do Peia } \\
\text { e costa continental }\end{array}$ & $\begin{array}{c}\text { Zona de } \\
\text { Recuperação }\end{array}$ & $\begin{array}{c}\text { Qualidade } \\
\text { visual Média }\end{array}$ \\
\hline 10 & $\begin{array}{l}\text { Costão rochoso } \\
\text { Saco Grande }\end{array}$ & $\begin{array}{c}\text { Lat: S } 23^{\circ} 32^{\prime} 45,8^{\prime \prime} \\
\text { Long: O } 45^{\circ} 03^{\prime} 25,9^{\prime \prime} \\
\text { Altitude: } 12 \mathrm{~m}\end{array}$ & $\begin{array}{l}\text { mar aberto, costão } \\
\text { rochoso, vegetação de } \\
\text { costão e encosta }\end{array}$ & $\begin{array}{l}\text { Zona de uso } \\
\text { Extensivo }\end{array}$ & $\begin{array}{l}\text { Qualidade } \\
\text { visual médio- } \\
\text { superior }\end{array}$ \\
\hline
\end{tabular}

Fonte: Autores (2015). Source: Authors (2015). 
Os pontos 1, 2 e 3 (praia do Sapateiro; píer e praia do Presídio) foram classificadas como Qualidade Visual Média (Figuras 4, 5 e 6 respectivamente), por apresentarem em suas respectivas paisagens interferência humana significativa, modificando amplamente o ambiente natural. No entanto, de acordo com o plano de manejo do PEIA, estes pontos estão localizados em zona de uso intensivo. Ou seja, são locais onde a presença de turistas e funcionários é consideravelmente alta em relação às demais zonas do parque, pois são locais de embarque e desembarque de pessoas, sendo estas mais suscetíveis aos impactos ambientais. Assim, foram classificados como de menor qualidade ambiental.

De acordo com a literatura técnica os impactos ambientais podem ser conceituados como: toda e qualquer alteração antrópica sofrida em um determinado local, por um determinado período, havendo alterações nas propriedades, físicas, químicas ou biológicas (SÁNCHEZ, 2013; WATHERN, 1988). Portanto, como se verificou 0 trecho frontal do PEIA apresenta vulnerabilidade suficiente para que alterações antrópicas se estabeleçam ao longo do tempo, alterando a comunidade áquatica e degradando o ecótono, isto é, a área de transição entre a vegetação terrestre e ambiente aquatico.

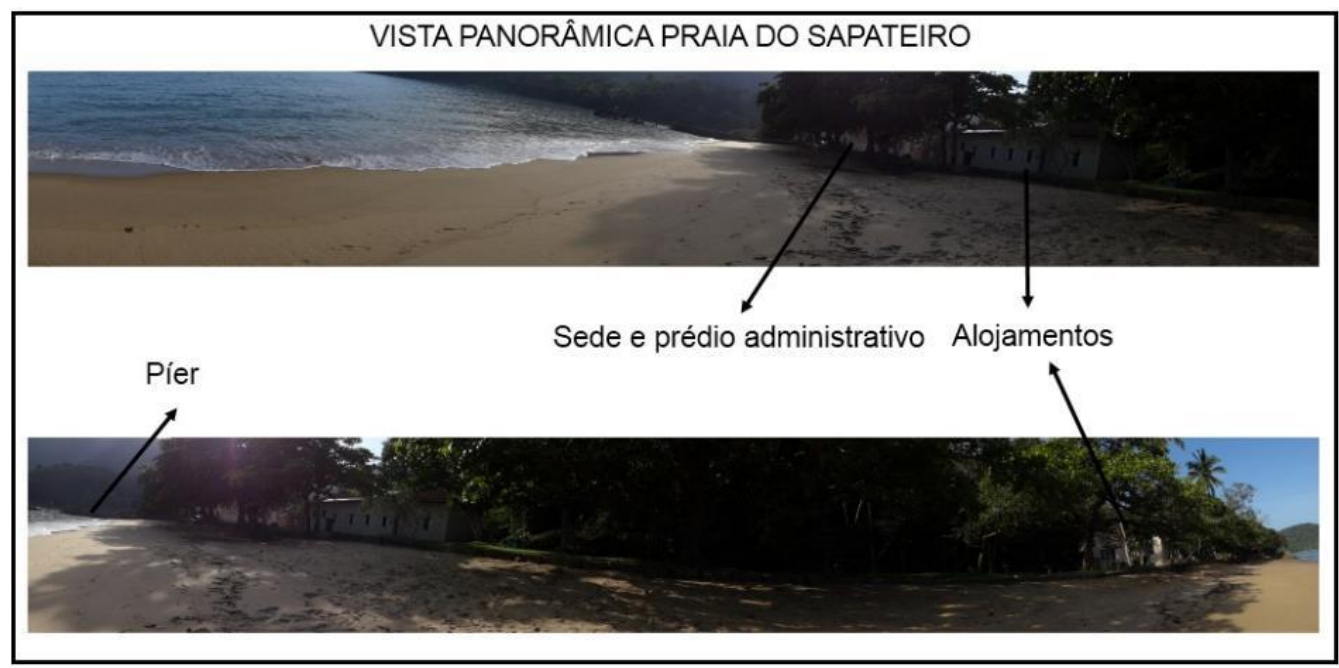

Figura 4: Vista da praia do Sapateiro. Figure 4: View of the Sapateiro beach Fonte: Autores (2015). Source: Authors (2015).

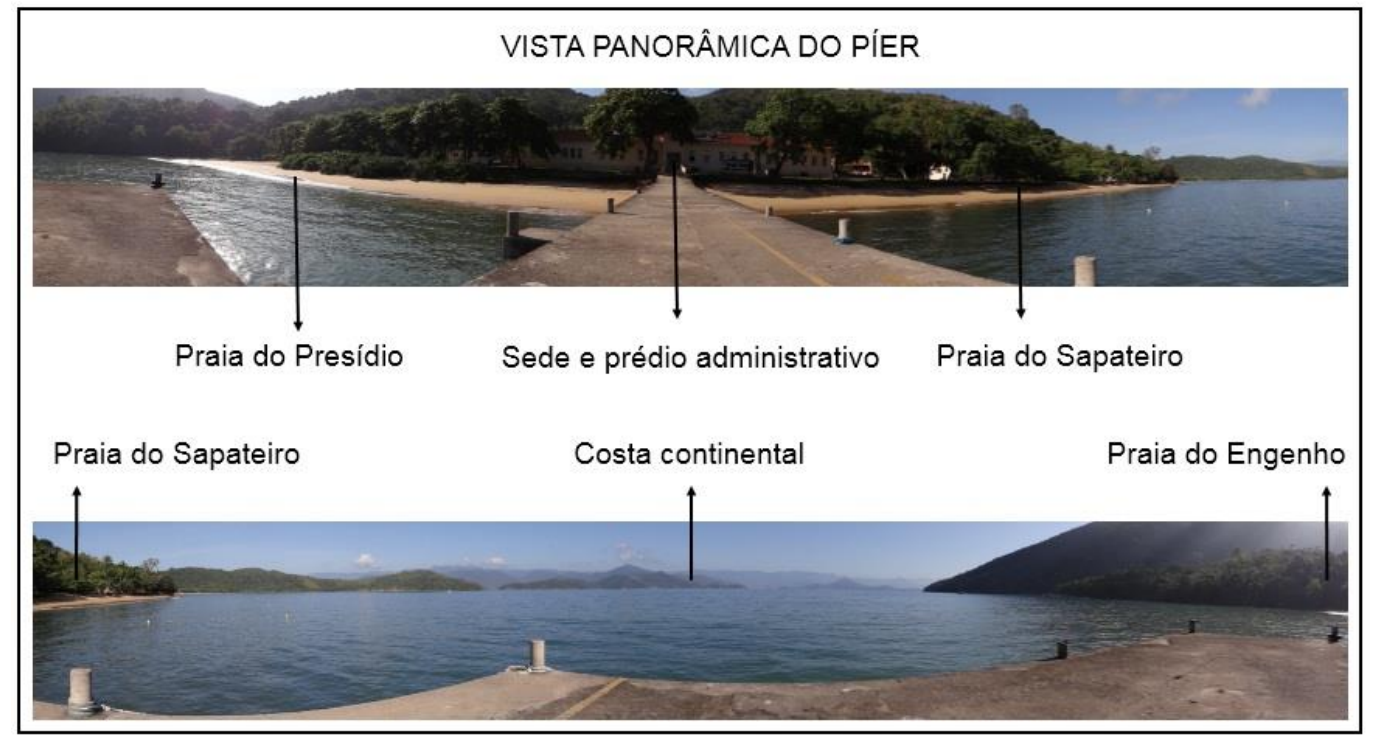

Figura 5: Vista do Píer. Figure 5: View of the pier

Fonte: Autores (2015). Source: Authors (2015). 


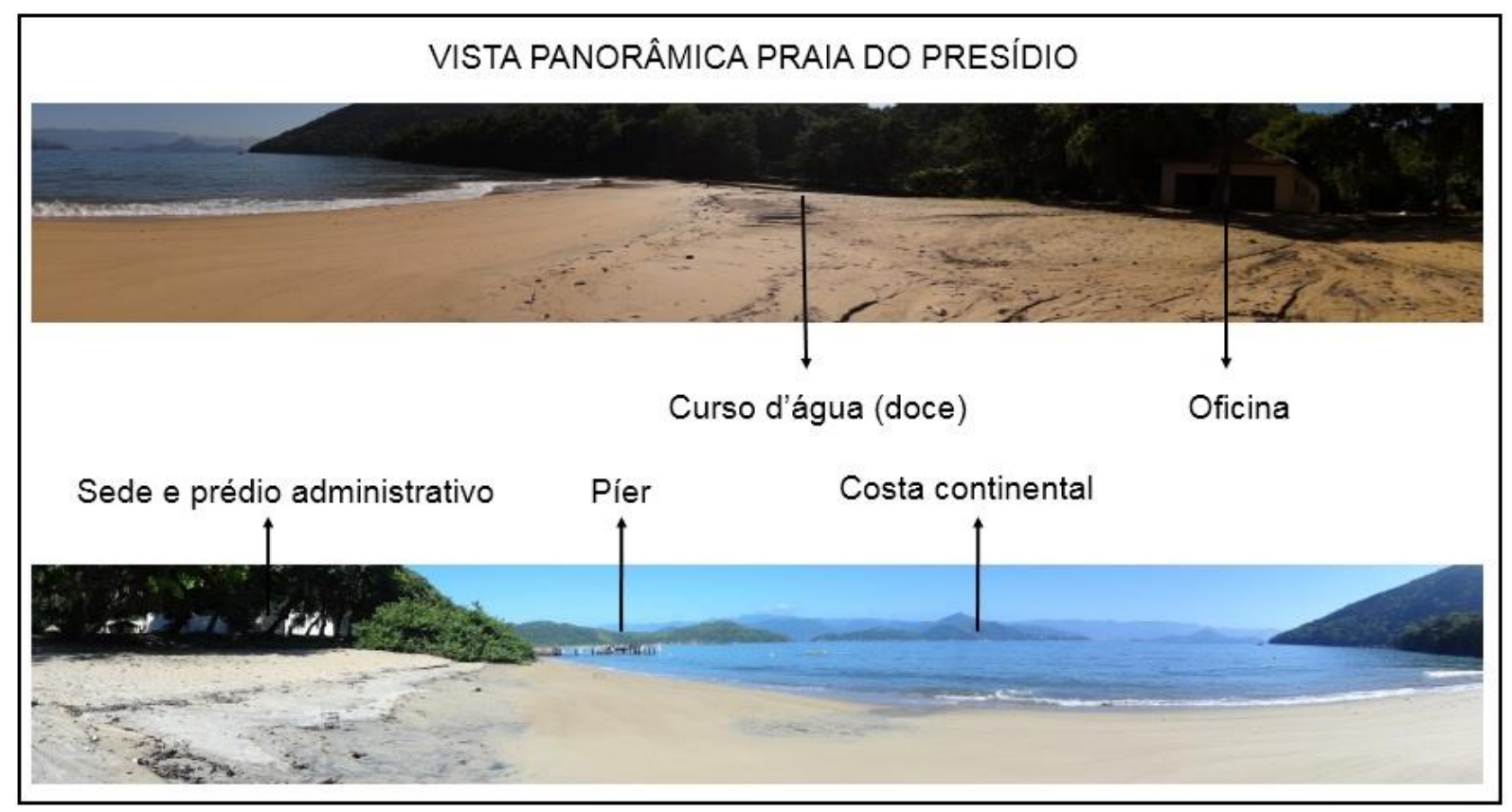

Figura 6: Vista da praia do Presídio. Figure 6: View of the Presídio beach Fonte: Autores (2015). Source: Authors (2015).

Em contrapartida, os pontos 4, 5, 7 e 10 (Mirante do Boqueirão, praias do Engenho e Sul e Costão rochoso do Saco Grande), receberam Qualidade Visual Média Superior (Figuras 7, 8, 9 e 10 respectivamente), pois apresentam excepcionais belezas, como a vista ao mar aberto e Boqueirão (local de travessia das embarcações que chegam ao PEIA), piscina e queda d'água natural, pôr-dosol e mínimas ações antrópicas.

Entretanto, estas paisagens localizam-se em zona de uso extensivo, as quais são utilizadas para recreações sustentáveis, tais como, trilhas sensoriais ou comentada, palestras, técnicas de mergulho, entre outros, caracterizando locais de maior frequência de banhistas. Contudo, a praia do Sul (ponto 7) é a mais distante da sede, à uma distância de $1.100 \mathrm{~m}$ (praias de acesso guiado), estando a maior parte do tempo utilizada por turistas de embarcações particulares, que não registram presença no parque. Portanto, pode-se concluir que o número de visitantes tem sido subestimado. Vale ressaltar que, a praia do Sul (Figura 9) não se caracteriza como uma enseada, a mesma possui 110 metros de extensão. As fotos registradas não possuem zoom e por isso, sua amplitude visual é maior, podendo dar falsa impressão de que as praias são menores, caracterizando-se como enseadas.

O costão rochoso do Saco Grande (ponto 10), é o ponto turístico (sem praia) mais distante da sede, com $1.300 \mathrm{~m}$, sendo acessado apenas por funcionários e pesquisadores. O Saco Grande é um local com elevada conservação ambiental, com vestígios de ações humanas apenas nas trilhas de acesso e situa-se na costa sul do parque, com vista do oceano aberto, com a possibilidade de vislumbrar o nascer do Sol. A razão por esta paisagem ser classificada como Qualidade Média Superior se deve ao fato de haver uma diversidade muito baixa em relação às ações humanas e relevo, já que o indicador de diversidade não visa apenas aspectos biológicos e físicos, mas a diversidade em forma de mosaico, incluindo o meio biótico, abiótico e antrópico. 


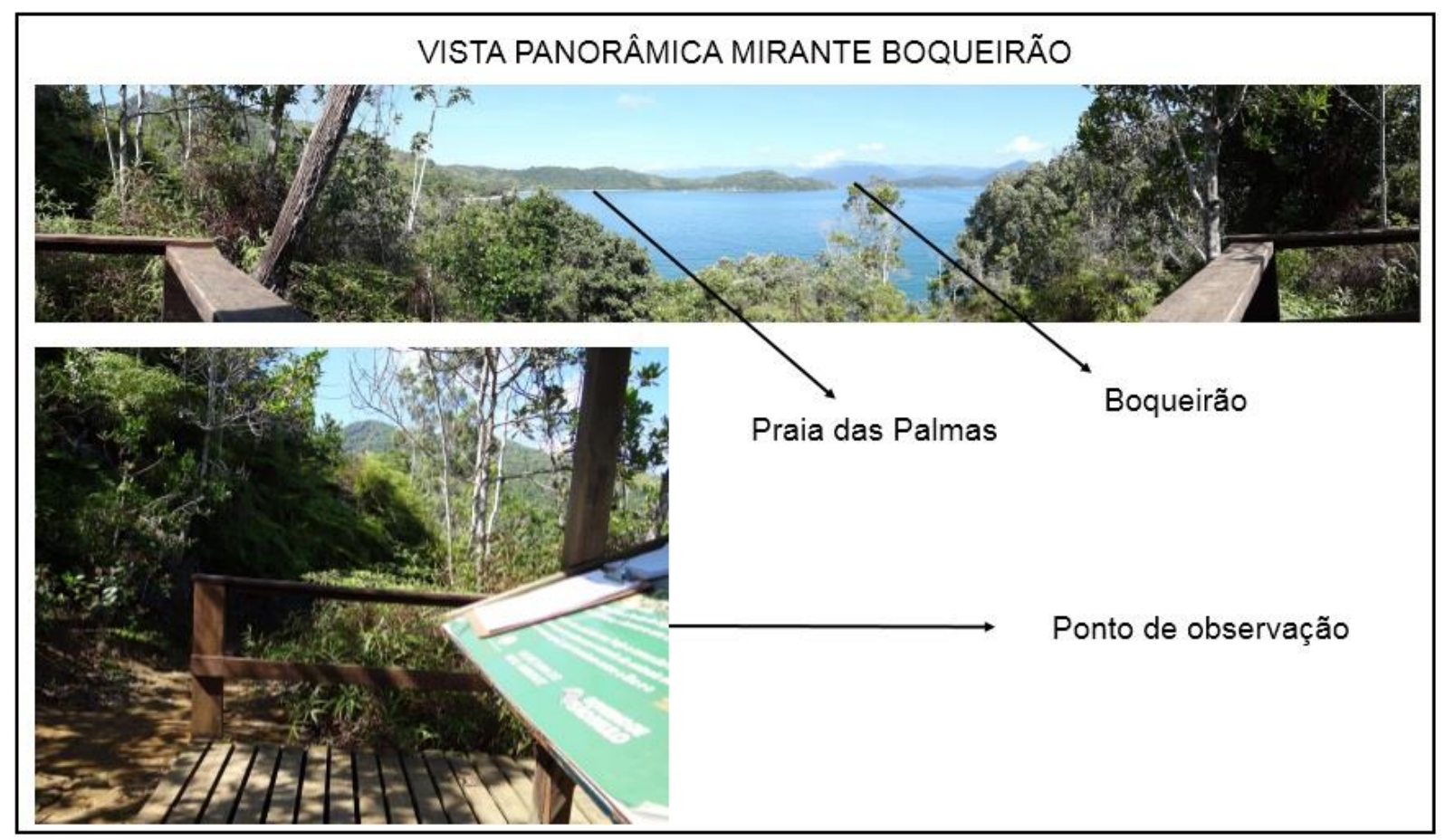

Figura 7: Vista do mirante do Boqueirão. Figure 7: View of the Boqueirão gazebo. Fonte: Autores (2015). Source: Authors (2015).

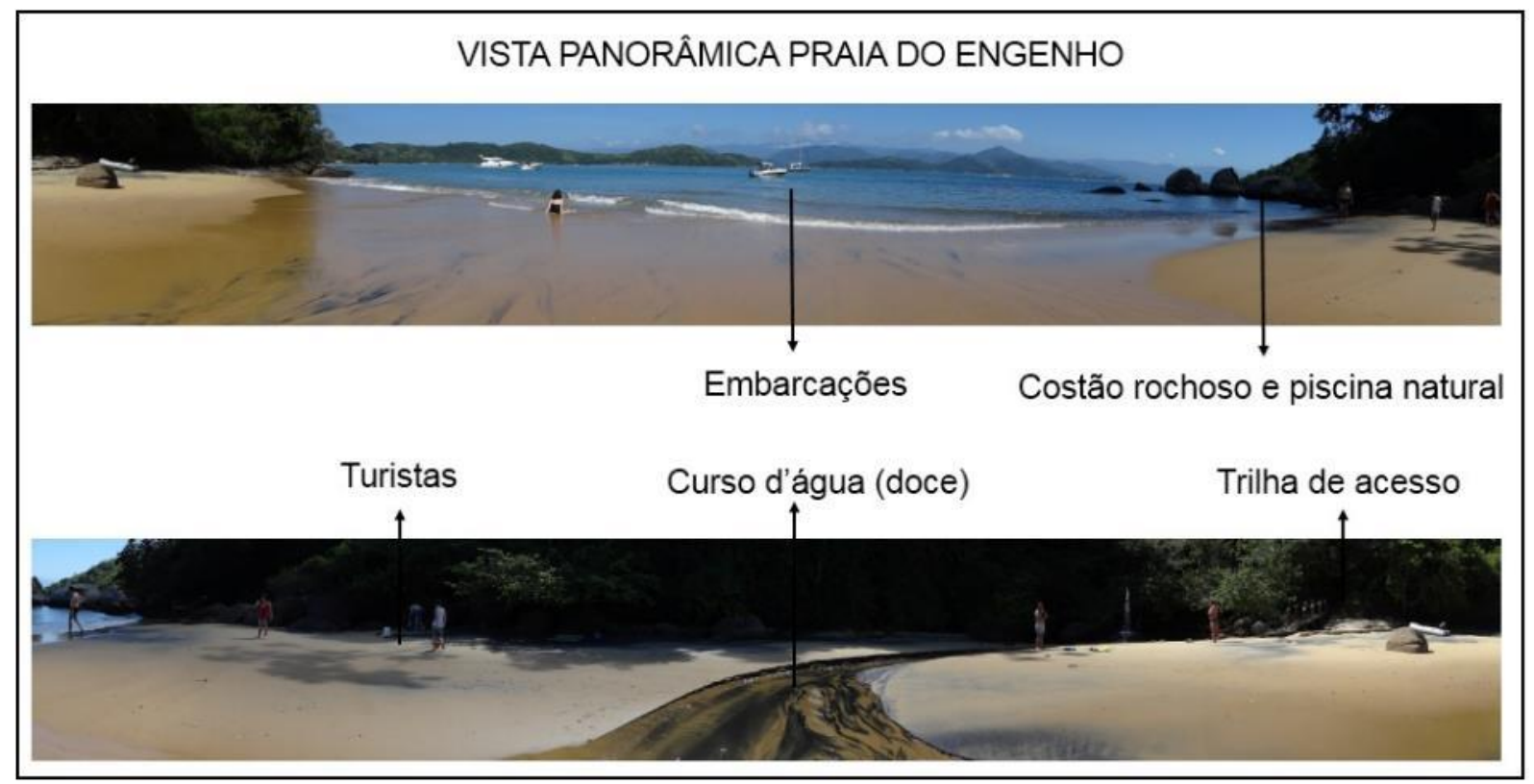

Figura 8: Vista da praia do Engenho. Figure 8: View of the Engenho beach.

Fonte: Autores (2015). Source: Authors (2015). 


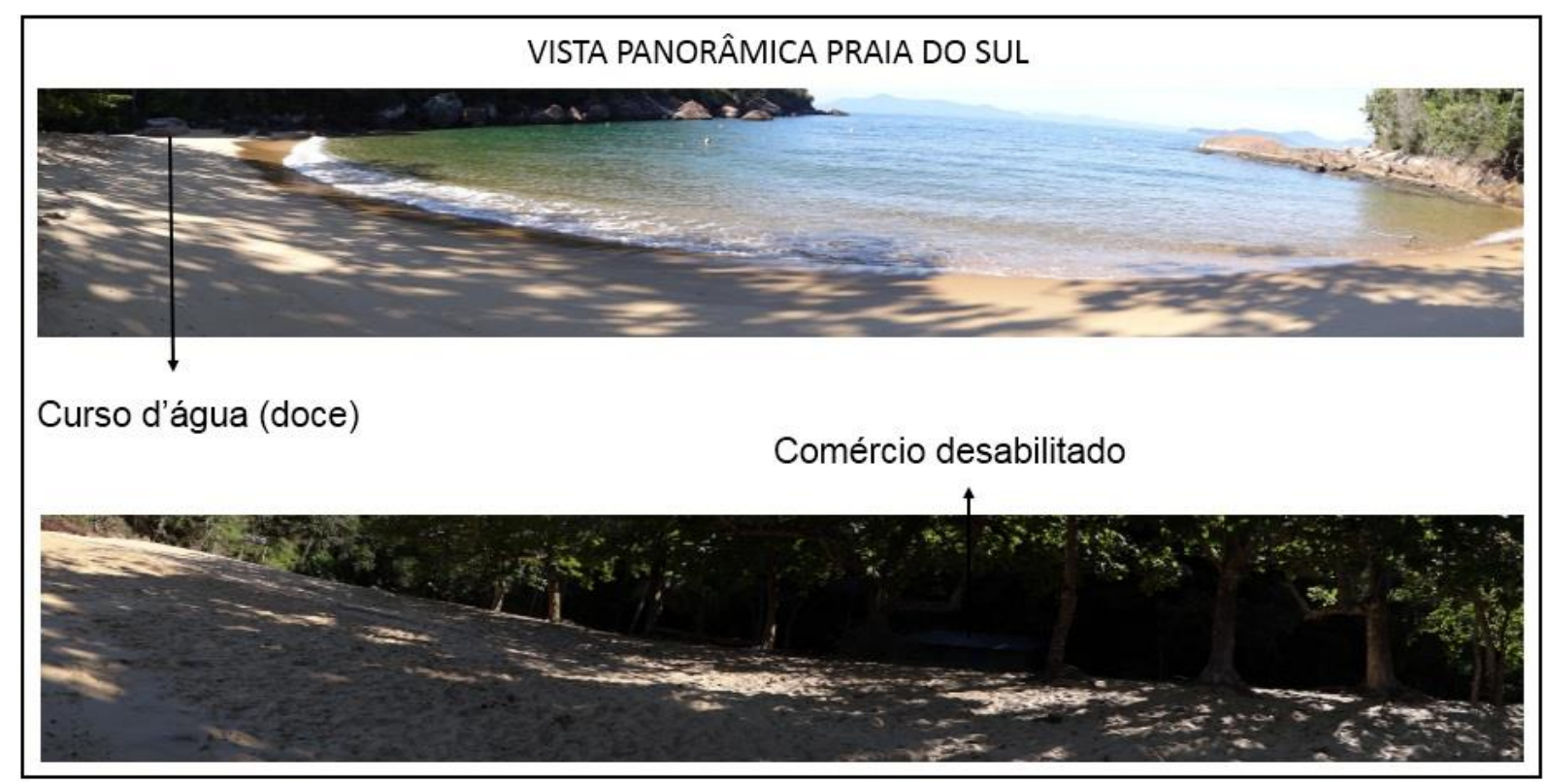

Figura 9: Vista da praia do Sul. Figure 9: View of the Sul praia.

Fonte: Autores (2015). Source: Authors (2015).

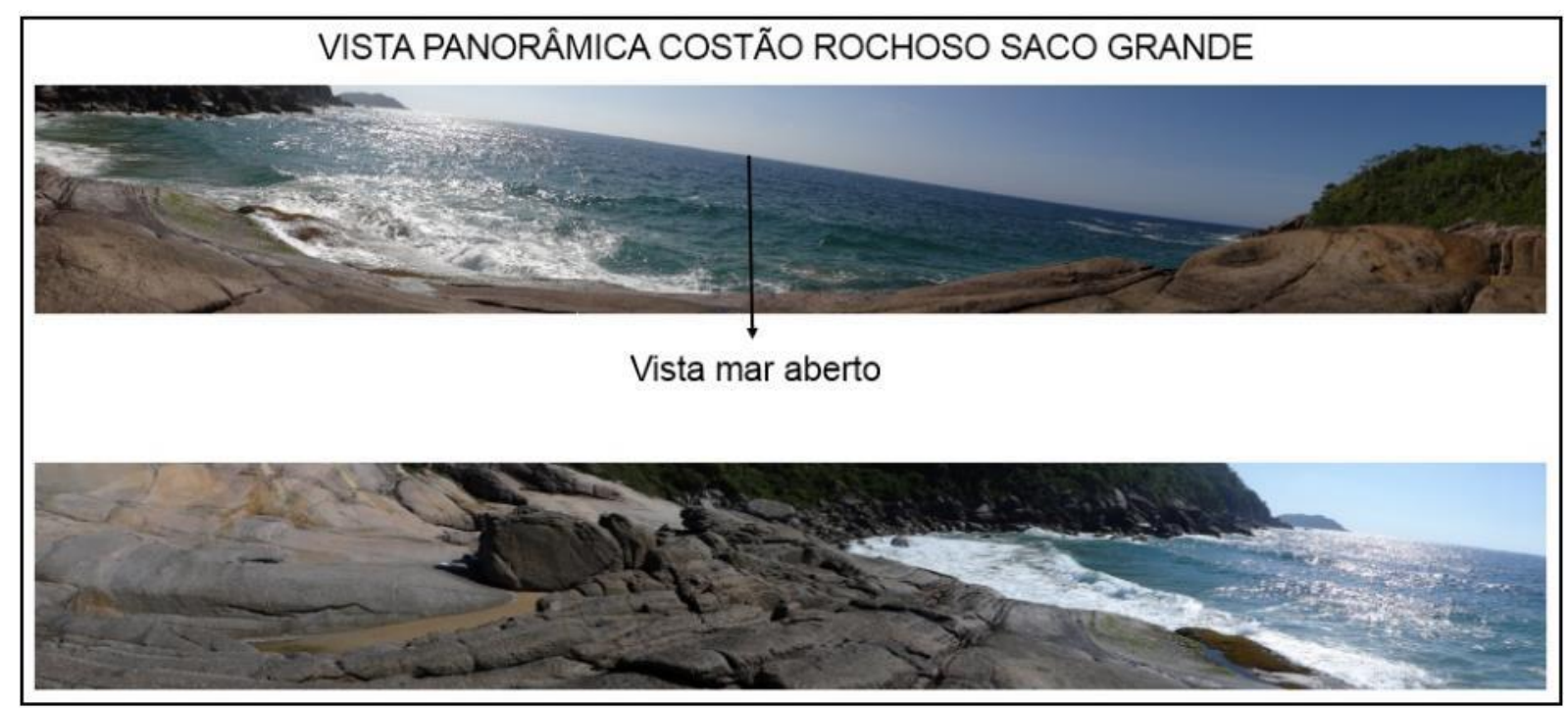

Figura 10: Vista do costão rochoso do Saco grande. Figure 10: View of the Saco Grande rocky shore. Fonte: Autores (2015). Source: Authors (2015).

A região classificada como "Zona de Recuperação" apresentou como representante o ponto 9 (mirante da Represa), que obteve a classificação mais baixa dentre as atribuídas, Qualidade Visual Média (Figura 11), devido à mesma estar localizada em uma região alta com vista para a parte frontal do parque e, de lá, pode-se identificar diversas ações antrópicas, acarretando detratores significativos para a paisagem, bem como média diversidade (relevo, vegetação, água e atividades humanas). Destaca-se ainda a presença de um represamento artificial à montante do mirante, propiciando área de alteração antrópica e consequentemente impactos ambientais, como a vegetação suprimida ou submergida para o represamento. Além de infraestrutura para abastecimento e geração de energia no parque. Porém, apesar dos impactos negativos, a paisagem se destaca pela visão ampla da ilha em relação ao continente. 
Por fim, dentre os 10 locais analisados, apenas os pontos 6 e 8 (mirante da praia das Palmas e a praia das Palmas) receberam classificação de Qualidade Visual Superior (maior classificação), devido aos baixos detratores observados, ações antrópicas adequadas e consideráveis para o ambiente, como trilhas e placas informativas e principalmente meio natural e alta relevância para educação ambiental (Figuras 12 e 13).

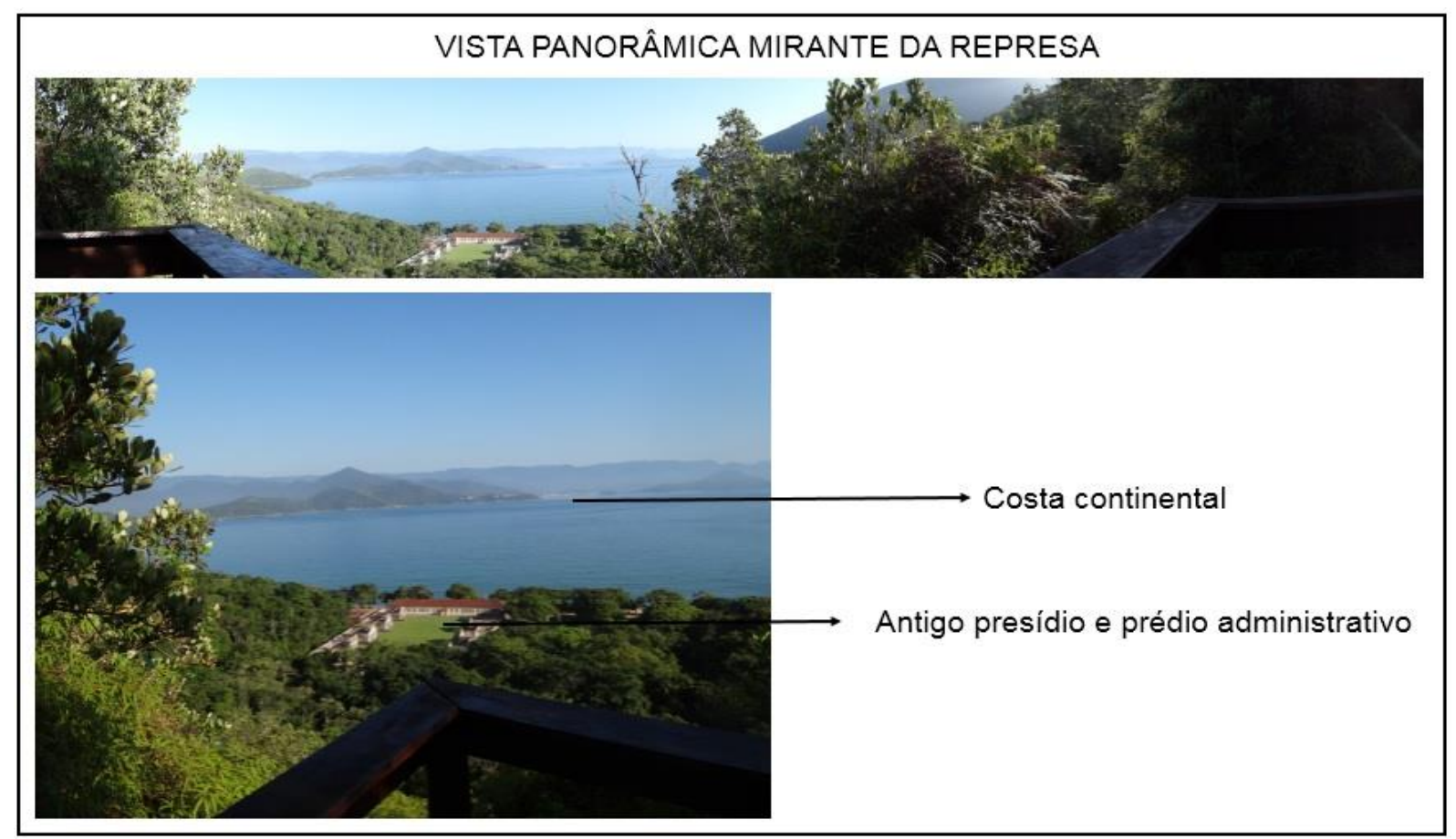

Figura 11: Vista do mirante da Represa. Figure 11: View of the Represa gazebo. Fonte: Autores (2015). Source: Authors (2015).

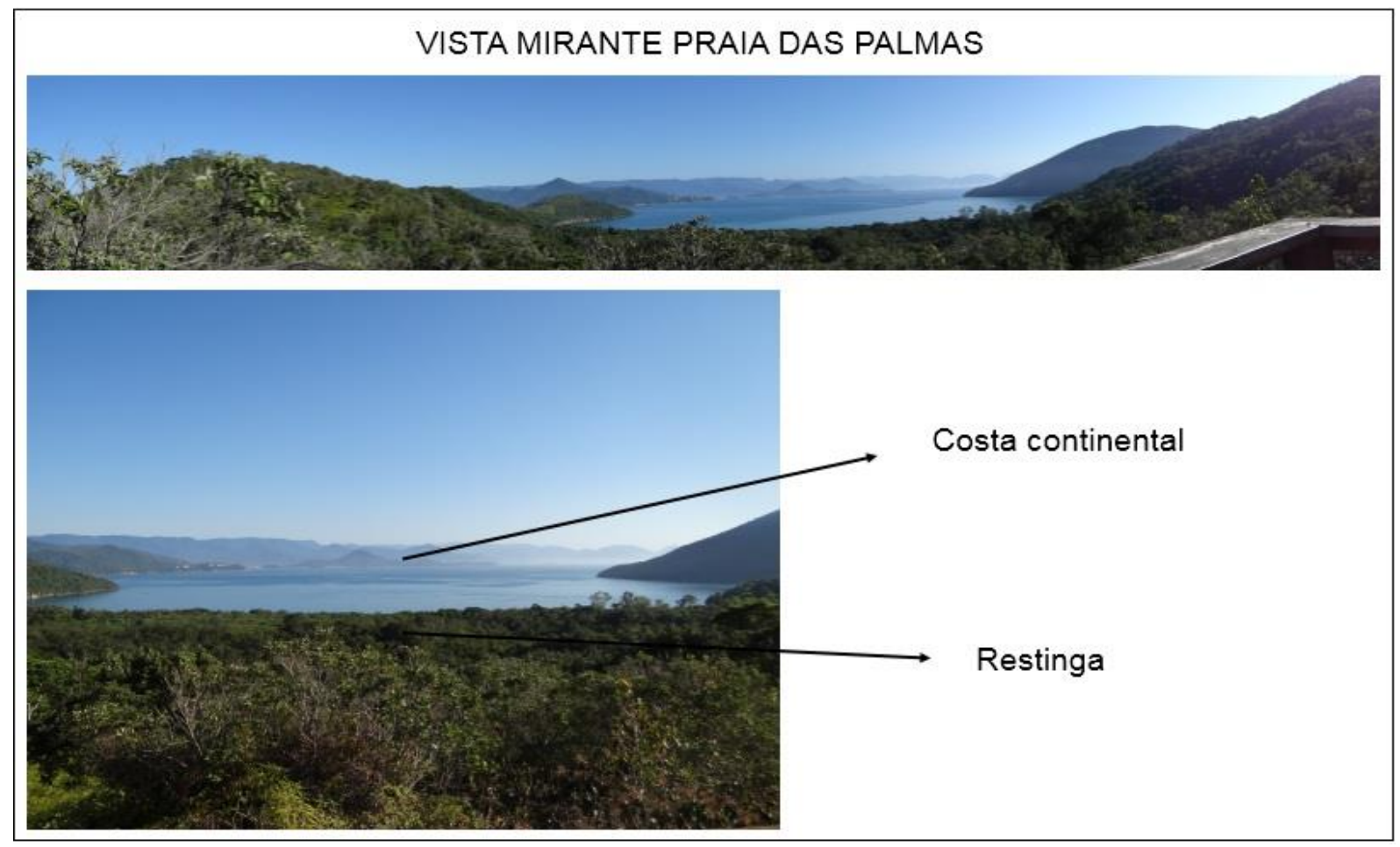

Figura 12: Vista do mirante da praia das Palmas. Figure 12: View of the Palmas beach gazebo. Fonte: Autores (2015). Source: Authors (2015). 


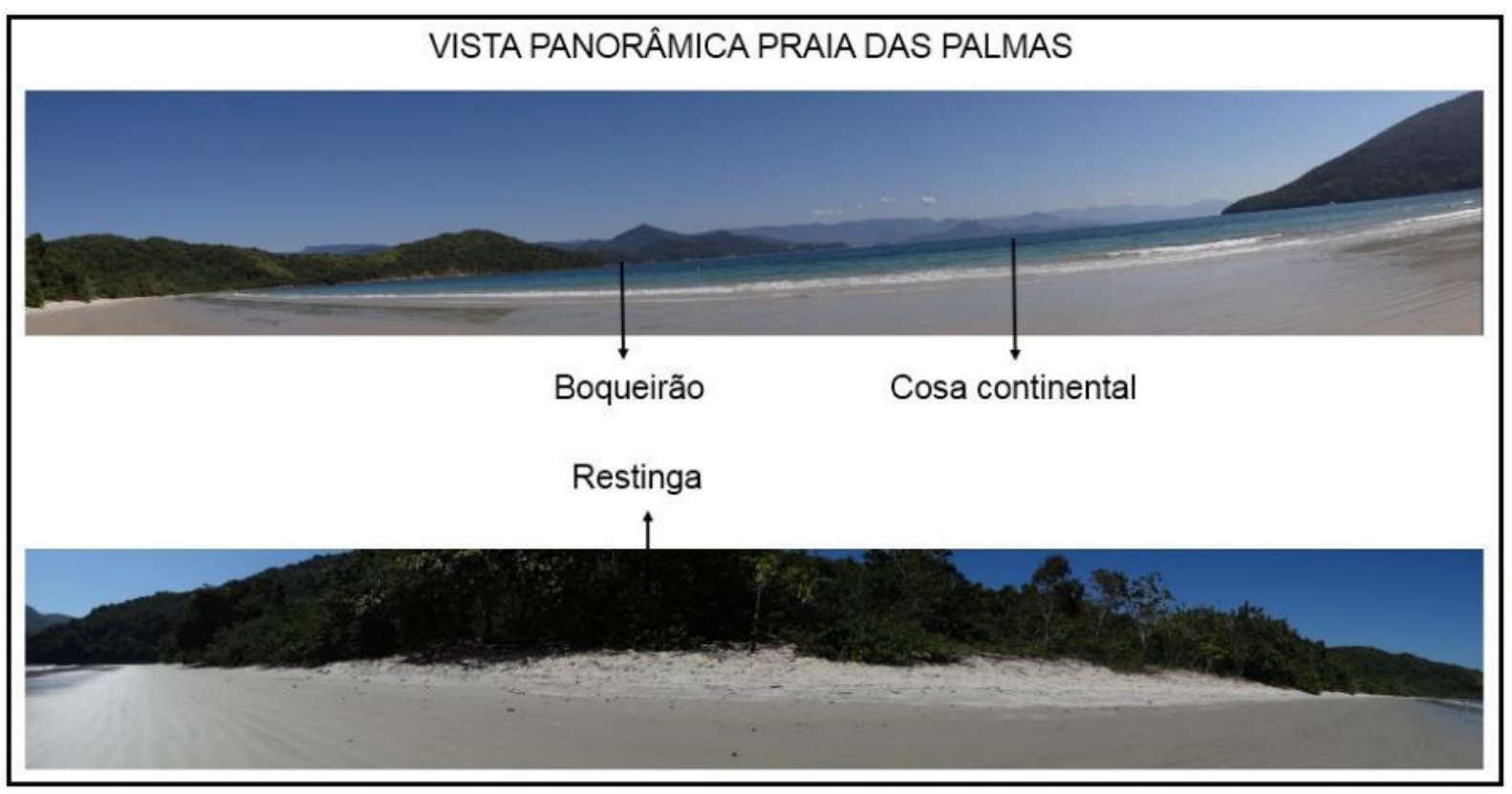

Figura 13: Vista da praia das Palmas. Figure13: View of the Palmas beach.

Fonte: Autores (2015). Source: Authors (2015).

\section{Análise e avaliação das paisagens}

Os indicadores analisados foram avaliados individualmente, comparando os componentes de cada paisagem e as notas atribuídas aos mesmos.

\section{a) Diversidade:}

Este indicador abrangeu uma escala de 0 a 60 , porém as notas máximas encontradas para as paisagens em análise foram 44 (Píer), 39 (praia do Presídio) e 38 (praias do Sapateiro e das Palmas), sendo todas elas classificadas como de "Alta Diversidade". As demais paisagens receberam classificação "Média Diversidade", com a menor nota registrada na praia do Sul (20). Esta divergência de classificações se deve principalmente pelo fato das paisagens frontais do PEIA (paisagens com as maiores pontuações citadas) contemplarem vistas mais amplas, além da elevada presença de diversas edificações (com exceção da praia das Palmas). Contudo, os resultados obtidos para o PEIA, de modo geral, distinguemse das pesquisas realizadas por Pires (2005) e Soares, Medeiros e Sales Filho (2014), que aplicaram esta metodologia no litoral de Santa Catarina (Porto Belo) e praia de Ponta Negra (Natal) no Rio Grande do Norte, respectivamente. Ambos locais situam-se em áreas continentais, públicas e não são áreas protegidas, abrangendo paisagens com mosaicos naturais e urbanizados, elevando a diversidade local. No caso do PEIA, uma área protegida, as paisagens apresentamse com mínimas alterações antrópicas na maior parte do parque, em relação às áreas citadas acima, o que acarretou em uma diversidade mais mediana, não constituindo na maior parte das paisagens um mosaico de aspectos bióticos, físicos e antrópicos. Desta forma, a diversidade do PEIA, apresenta-se inferior às encontradas no trabalhos do Rio Grande do Norte e Santa Catarina, porém este resultado é satisfatória por se tratar de área protegida 


\section{b) Naturalidade:}

Nos 10 pontos analisados, seis deles apresentaram classificação superior quanto a sua naturalidade, e os demais receberam qualidade média superior. Os pontos dos Mirantes do Boqueirão, Represa e Palmas, praias das Palmas, Engenho e Sul, bem como o costão rochoso do Saco Grande foram os que receberam qualidade superior. Estes constituem vegetação mais conservada, além de apresentarem mínimas alterações antrópicas, resultando em uma maior interação entre meio físico e biótico, podendo garantir assim um maior equilíbrio ecológico. Griffth (1983) acredita que a conservação das paisagens cênicas conta a história de um lugar, sendo que seus aspectos naturais podem ser objetos de planos e de ações controladas levando a uma maior integridade ambiental. Nos trabalhos de Pires (2005) e Soares, Medeiros e Sales Filho (2014), a proporção de paisagens de naturalidade superior foi significativamente menor em relação ao diagnosticado no PEIA, isto devido a esses ambientes estarem em áreas urbanas.

\section{c) Singularidade:}

A unicidade, raridade, excepcionalidade, e demais características de um ambiente singular, tanto ambiental, quanto cultural representam os parâmetros deste indicador. Observou-se que as atribuições de notas divergiram pouco, em uma escala de 0 a 1 para cada variável, tendo como mínimo e máximo 3,5 e 5,1 respectivamente, de modo que todas as paisagens foram enquadradas em "Razoável potencial de atratividade turística em nível estadual e subnacional" (RES). Os destaques das paisagens do PEIA são nascer e pôr-do-Sol no costão rochoso do Saco Grande e praia do Sul respectivamente, presença de edificações históricas e culturais no píer e nas praias do Sapateiro e do Presídio; presença de fauna e flora nativas e vistas amplas e panorâmicas do entorno do PEIA, bem como da costa continental dos três mirantes analisados. Contudo, os trabalhos aplicados pelos autores citados acima contemplam paisagens nos três parâmetros de classificação, mostrando que o PEIA apresenta ambientes singulares por estarem distantes de mosaicos urbanos.

\section{d) Detratores:}

Quase todas as paisagens analisadas apresentaram algum tipo de detrator (representam o quão impactante está a paisagem observada, por meio de artificializações, edificações e ações antrópicas como um todo), o que influenciou de forma negativa na avaliação. O píer foi o único ponto que recebeu a classificação de grandes detratores, pois ali estão presentes o museu; os banheiros; a sede do PEIA; os alojamentos; a capela e o próprio píer, sendo estes componentes resultantes de ação antrópica que imprimem um aspecto artificial da paisagem levando a um distanciamento das condições naturais. As praias do Presídio e do Sapateiro, que ficam próximas ao píer, receberam classificação de conjunto de médio detratores. Apesar de estarem próximos a atividades humanas, apresentam também valores e componentes naturais na paisagem, como por exemplo, as praias e a restinga. Pires (2005) e Soares, Medeiros e Sales Filho (2014), puderam encontrar também detratores relacionados à artificialização da área, como galpões de marinas e da fábrica de pescados, construções nas encostas elevadas dos morros, caminhos e escavações localizadas nas encostas dos morros, hotéis e 
condomínios residenciais, considerando estas intervenções antrópicas comuns em locais de turismo. Entretanto, esses autores não apontaram essas intervenções como um impacto inteiramente negativo ao ambiente, pois no caso da praia de Ponta Negra, a legislação resguarda a conservação da paisagem e impede que o seu uso e apropriação sejam apenas daqueles que estão na faixa da praia.

Os demais pontos do PEIA receberam classificação de pequenos a médios detratores, sendo os pontos onde se tem maior conservação da paisagem e de seus aspectos naturais, apresentando apenas circulação de turistas, as trilhas e as embarcações particulares. Na pesquisa realizada por Pereira Silva, Oliveira e Saito (2012), no Parque Nacional da Chapada dos Veadeiros - GO, visando ao diagnóstico da qualidade cênica das paisagens como contribuição para gestão de trilhas, os autores concluíram que os planos de utilização e manejo de parques e ambientes naturais devem compor aspectos preservacionistas não apenas in situ, mas o entorno das paisagens e todo o campo de visão, bem como o tratamento paisagístico de áreas degradadas.

Entretanto, o plano de manejo do PEIA já contabiliza aproximadamente 26 anos de vigência, o que contrapõe o exposto por Alves (1996), mencionando a necessidade de atualização do mesmo a cada cinco anos, com participação da comunidade local e de pesquisadores multidisciplinares. De acordo com Medeiros e Pereira (2011), que realizaram um trabalho com planos de manejo do estado do Rio de Janeiro, o aperfeiçoamento destes documentos continua precário em todo Brasil, destacando-se como principais deficiências: a elaboração de um plano de manejo no período de até cinco anos após a criação da UC; revisão do mesmo a cada cinco anos; elaboração e publicação no período máximo de 18 meses; execução do planejamento proposto no plano de manejo anterior e adequação de toda a área do parque ao zoneamento ambiental.

\section{Conclusão}

O PEIA é um dos parques estaduais mais visitados do estado de São Paulo, contendo paisagens que se encontram em diferentes altitudes, fitofisionomias, aspectos abióticos, níveis de fluxo turístico e zonas de uso público. Porém, ressaltase que esse número de visitantes deve estar subestimado, uma vez que não há controle de visitantes que chegam de barco diretamente na praia do Sul.

Verificou-se que as paisagens localizadas nas zonas de uso intensivo, receberam classificação de qualidade visual média em três dos quatro pontos selecionados. Esta foi a menor classificação encontrada, devido principalmente ao uso antrópico intensivo nesses locais como, construções, recreação nas praias e trilhas, deposição de rejeitos, transição de embarcações, dentre outras ações. A praia das Palmas foi a única paisagem localizada nesta zona a receber uma classificação distinta (qualidade visual superior), por permitir um campo de visão amplo, com reduzidas ações humanas, diversidade elevada e conservação em destaque em meio ao mosaico de restinga, encosta da Serra do Mar e do mar.

A zona de uso extensivo, definida por locais de relevância educacional e de transição entre a sede e os demais pontos turísticos do PEIA, apresentou cinco paisagens, sendo quatro delas classificadas como qualidade visual média superior e uma de qualidade visual superior (mirante da praia das Palmas). Notou-se que estas paisagens mais distantes da sede, com um fluxo turístico reduzido em relação 
às demais paisagens, apresentaram maior qualidade visual da paisagem, evidenciando que a limitação do homem aos ambientes naturais resguarda um nível de preservação mais elevado.

Por fim, a zona de recuperação apresentou a paisagem do mirante da Represa, localizada na parte frontal do PEIA há aproximadamente $73 \mathrm{~m}$ de altitude, sendo classificada como qualidade visual média, por apresentar diversos detratores ao seu redor como a própria represa, e a vista quase que total de toda parte administrativa e edificada do PEIA.

De modo geral, o PEIA apresenta paisagens singulares quando comparada às pesquisas similares feitas em ambientes mais urbanizados, por ser uma unidade de conservação, porém, a interferência humana reflete efetivamente nas paisagens. A permanência da maioria dos banhistas se dá nas praias do Engenho, Palmas e Sul, tornando as mesmas mais susceptíveis a ação antrópica, no entanto, de acordo com o zoneamento as praias do Engenho e do Sul, que estão enquadradas como de uso extensivo deveriam ser inseridas no zoneamento de uso intensivo por apresentarem elevada permanência de banhistas.

Sendo assim, o trabalho possibilitou contrastar os procedimentos políticos adotados nesta UC com a realidade ambiental instaurada dia-a-dia, em um parque que concerne visitação pública. Notoriamente a ausência de uma atualização do plano de manejo, vem acarretando acomodações nos impactos negativos das paisagens. Portanto, sugere-se maior efetividade na aplicação da política estadual no ecoturismo do PEIA, atentando-se a configuração do zoneamento ambiental, para com os princípios conservacionistas.

\section{Referências bibliográficas}

ALVES, K. R. 1996. Uma Visão Geral das Unidades de Conservação no Brasil. In. RAMOS A.; CAPOBIANCO, J. P. Unidades de Conservação no Brasil: aspectos gerais, experiências inovadoras e a nova legislação (SNUC). Documentos do ISA. no $01 . \quad$ Disponível em: $<$ https://www.socioambiental.org/sites/blog.socioambiental.org/files/publicacoes/10 100.pdf >. Acesso em: 03 abr. 2015.

BENSUSAN, N. Conservação da biodiversidades em áreas protegidas. Ed. FGV: Rio de Janeiro. 2006, 176 p.

BERNARD, E.; PENNA, L.A.O.; ARAÚJO, E. Downgrading, Downsizing, Degazettement, and Reclassification of Protected Areas in Brazil. Conservation Biology. v. 28, n. 4, p. 939-950, 2014. DOI: 10.1111/cobi.12298.

Brasil. 2000. Lei no 9.985, de 18 de julho de 2000. Regulamenta o art. 225, § 1으, incisos I, II, III e VII da Constituição Federal, institui o Sistema Nacional de Unidades de Conservação da Natureza e dá outras providências. Brasília jul/2000.

BROCKEMAN, W.Y.; GRIFFITHS, M.; RAO, M.; RUF, R.; SALAFSKY, N. Enforcement mechanisms. In: ed. TERBORGH, J.; SCHAIK, G.V.; DAVENPORT, L.; RAO, M. Making Parks Work. Island press: Washington, DC, 2002, $265-278$. 
BRUNER, A.G.; GULLISON, R.; RICE, R.; DA FONSECA, G. Effectiveness of Parks in Protecting Tropical Biodiversity. Science. v. 291, n. 5501, p. 125-128, 2001. DOI:10.1126/science.291.5501.125.

BUTCHART S.H.M.; WALPOLE, M.; COLLEN, B.; STREIN. A.V.; SCHARLEMANN J.P.W.; ALMOND, R.E.A.; BAILLIE, J.; BOMHARD, B.; BROWN, C.; BRUNO, J.; ARPENTER, K.; CARR, G.M.; CHANSON, J.; CHENERY, C.; CSIRKE, J.; DAVIDSON, N.C.; DENTENER, F.; FOSTER, M. GALLI, A; GALLOWAY, J.N.; GENOVESI, P; GREGORY, R.; HOCKINGS, M.; KAPOS, V.; LAMARQUE J.F.; LEVERINGTON, F.; LOH, J.; MCGEOGH, M.; MCRAE, L.; MINASYAN, A.; MORCILLO, M.H.; OLDFIELD, T; PAULY, D.; QUADER, S.; REVENGA, C.; SAUER, J.; SKOLNIK, B.; SPEAR, D.; STANWELL-SMITH, D.; SYMES, A.; SPEAR, D.; STUART, S.;.TYRRELL, T.D.; VIE, J.C.; WATSON, R. Global Biodiversity: Indicators of recent declines. Science. v. 328, n. 5982, p. 1164-1168, 2010. DOI: 10.1126/science.1187512.

DAVEY, A. G. National System Planning for Protected Areas. IUCN International Union for the Conservation of Nature and Natural Resources. Switzerland and Cambridge, 71 p., 1998. Disponível em: $<$ https://portals.iucn.org/library/efiles/documents/PAG-001.pdf >. Acesso em: 15 set. de 2015.

ESTEVES, C.F. Influência antrópica na distribuição espacial da comunidade de mamíferos no Parque Estadual da llha Anchieta, SP. 2010. Dissertação (Mestrado em Ciências Biológicas) - Universidade estadual de São Paulo, Rio Claro - SP, 2010.

FONT, J.N. Turismo, percepción del paisaje y planificación del territorio. Estudios Turisticos. v. 115, p. 45-54, 1992.

GIL, A. C. 2008. Métodos e técnicas de pesquisa social. Atlas, 6. ed., São Paulo.

GRIFFTH, J.J. 1983. Análise dos recursos visuais do Parque Nacional de Caparaó.

Revista Floresta. v. 14, n. 2, p. 15-21, 1983.

GUILLAUMON, J.R.; MARCONDES, M.A.P.; NEGREIROS, O.C.; MOTA, I.S.; EMMERICH, W.; BARBOSA, A.F.; BRANCO, I.H. D.C.; CAMARA, J.J.C.; OSTINI, S.; PEREIRA, R.T.L.; SCORVO FILHO, J.D.; SHIMOMICHI, P.Y.; SILVA, D.A.; MELO NETO, J.E. Plano de Manejo do Parque Estadual da Ilha Anchieta. IF-Série Registros. n. 1, p. 1-103, 1989.

GURGEL, H.C.; FERREIRA, N.J.; LUIZ, A.J.B. Estudo da variabilidade do NDVI sobre o Brasil, utilizando-se a análise de agrupamentos. Revista Brasileira de Engenharia Agrícola e Ambiental. v. 7, n. 1, p. 85-90, 2003.

HECTOR, A.; BAGCHI, R. Biodiversity and ecosystem multifunctionality. Nature. Londres, v. 448, p. 188-191, 2007. DOl:10.1038/nature05947.

IBGE - Instituto Brasileiro de Geografia e Estatística. 2015. Caracterização populacional do município de Ubatuba-SP, Disponível em: <http://cod.ibge.gov.br/233/8>. Acesso em: 10 mar. de 2015.

KATAOKA, S.Y. Indicadores da qualidade da experiência do visitante no Parque Estadual da Ilha Anchieta. Dissertação (Mestrado em Recursos Florestais), Escola Superior de Agricultura Luiz de Queiroz/USP. São Paulo, 2004. 
KATAOKA, S.Y.; MAGRO, T.C.; BOBBERT, L.Y.; MACIEL, L.; SILVA FILHO, D.F. Ilha Anchieta State Park - Visitor experience quality assessment. Revista Instituto Florestal. v. 23, n. 1, p. 137-147, 2011.

KAUARK, F.S.; MANHÃES, F.C.; MEDEIROS, C.H. 2010. Metodologia da pesquisa: Um guia prático. Itabuna/BA: Via Litterarum, 2010. 89 p.

KOGA, E.S.; OLIVEIRA, C.S.; KANESHIRO, D.M. Programa de capacitação do Projeto de Ecoturismo na Mata Atlântica no entorno dos parques estaduais paulistas. Revista Brasileira de Ecoturismo. v. 6, n. 1, p. 255-268, 2013.

MACHADO, L.M.C.P. Qualidade ambiental: indicadores quantitativos e perceptivos. In: MARTOS, H. L.; Maia, N. B. (coord.). Indicadores ambientais. Sorocaba: Martos, 1997. p. 15-21.

MCIT/MMA - Ministério do Comércio, Industria e Transporte/ Ministério do Meio Ambiente - Diretrizes para uma política nacional do ecoturismo. EMBRATUR/IBAMA. Disponível em: $<$ http://www.mma.gov.br/estruturas/sedr proecotur/ publicacao/140 publicacao20 082009043710.pdf>. Acesso em: 10 mar. de 2015.

MEDEIROS, R.; PEREIRA, G. S. Evolução e implementação dos planos de manejo em parques nacionais no estado do Rio de Janeiro. Revista Árvore. v. 35, n. 2, p. 279-288, 2011.

MEDEIROS, R. Evolução das tipologias e categorias de Áreas Protegidas no Brasil. Ambiente e Sociedade. v. 9, n. 1, p. $41-64,2006$.

OLIVEIRA, C.F. Ecoturismo como prática para o desenvolvimento socioambiental. Revista Brasileira de Ecoturismo. v.4, n. 2, p. 184-195, 2011.

PEREIRA SILVA, R.G.; OLIVEIRA, C.H.; SAITO, C.H. Análise cênica e diversidade visual de paisagens: contribuições para a gestão das trilhas turísticas no Parque Nacional da Chapada dos Veadeiros - GO. Sustentabilidade em Debate. v. 3, n. 2, p. 71-92, 2012.

PIRES, P.S. A. Análise de indicadores da qualidade visual como etapa da caracterização de paisagens turísticas: uma aplicação no distrito-sede de Porto Belo - SC. Turismo: Visão e Ação. v. 7, n. 3, p. 417 - 426, 2005..

PÓLIS - Instituto de Estudos, Formação e Assessoria em Políticas Sociais. 2013. Diagnóstico urbano socioambiental de Ubatuba. In: Litoral Sustentável: Desenvolvimento com inclusão social. Disponível em $<$ http://litoralsustentavel.org.br/wp-content/uploads/2013/04/1.Ubatuba 19.03.13.pdf. Acesso em 12/03/2015>. Acesso em 07 mai. 2015.

PRATES, A. P. L. Desafios para atingir as metas e o status do Sistema Nacional de Unidades de Conservação - SNUC. In: CONGRESSO BRASILEIRO DE UNIDADES DE CONSERVAÇÃO, 7. 2012, Natal - RN. Anais, Natal, 2012.

ROCHA, L.G.M.; DRUMMOND, J.A.; GANEM, R.S. Parques nacionais brasileiros: Problemas fundiários e alternativas para sua solução. Revista de Sociologia e Política. Curitiba, v. 18, n. 36, p. 205-226, 2010.

SÁNCHEZ, L.H. Avaliação de impacto ambiental: conceitos e métodos. 2. ed. São Paulo - SP: Oficina de Textos. 2013. 583 p. 
SÃO PAULO. Decreto Estadual no 51453, de 29 de dezembro de 2006. Cria o Sistema Estadual de Florestas - Sieflor e dá providencias correlatas. São Paulo. dez/2006.

SARTIFI, G.; SANO, N.N. Comparative Study of Tourism Management in State Parks Alto da Ribeira (PETAR) and Intervales (PEI). Turismo em Análise. v. 23, n.1, p. 207-237, 2012

SOARES, I.A; MEDEIROS, C.S.C; SALES FILHO, A. Análise de paisagem turística da praia de ponta negra(Natal-RN) com a utilização de indicadores visuais de qualidade: uma contribuição para o turismo sustentável. Revista Holos. v. 1. p. 228-246, 2014.

SOUZA, D.I.; MULLER, D.M.; FRACASSI, M.A.T.; ROMEIRO, S.B B. 2013. Manual de orientações para projetos de pesquisa. ESLSVC. Novo Hamburgo - RS.

SOUZA, N.L. Unidades de conservação em áreas urbanas - $O$ caso do Parque Cinturão Verde de Cianorte - Módulo Mandhuy. Revista O Espaço Geográfico em Análise. Curitiba - PR, v. 23, p. 448-488, 2011.

SPELTA, L.M.P.B. Avaliação das alterações na estrutura da comunidade Bentônica relacionadas à visitação pública na piscina natural do Parque Estadual da llha Anchieta, Ubatuba-SP. 2007. Dissertação (Mestrado em Botânica), Universidade de São Paulo, São Paulo, 2011.

TOMANIK, G.B.; NAKAGAWA, A.D.S. Ecoturismo e etiqueta ambiental. Anais, VIII Congresso Nacional de Ecoturismo e do IV Encontro Interdisciplinar de Ecoturismo em Unidades de Conservação. Revista Brasileira de Ecoturismo. n. 4 v. 4, p. 580, 2011.

VERGARA, S.C. Projetos e Relatórios de Pesquisa em Administração. Atlas, 3. ed. São Paulo, 2000.

UNEP-WCMC - United Nations Environment Programme - World Conservation Monitoring Centre. State of the world's protected areas: an annual review of global conservation progress. Cambridge, UK. 38 p., 2008. Disponivel em: $<$ http://old.unep-wcmc.org/state-world-protected-areas 137.html >. Acesso em: set. de 2015.

WATHERN, P. Na introductory guide to EIA. In: WATHERN, P. (Org.) Environmental impact assessment: theory and practice. London: Unwin Hyman, 1988, p. 3-30.

\section{Agradecimentos}

Agradecemos primeiramente a gestora do Parque Estadual da llha Anchieta, Priscila Saviolo Moreira, que nos recebeu e permitiu a realização de nosso trabalho, de forma a colaborarmos para a conservação e proteção do PEIA, bem como auxiliar uma possível atualização do plano de manejo. Agradecemos também a ONG Projeto Caravela que nos deu a oportunidade de executar este trabalho, e por fim e não menos importante, nosso agradecimento a Universidade Federal de Itajubá pela parceria através dos instrumentos cedidos para execução do projeto. 
Leonardo Silva Junior: Universidade Federal de Itajubá, Itajubá, MG, Brasil.

E-mail: leonardosilva_biologia@hotmail.com

Link para o currículo Lattes: http://lattes.cnpq.br/1683561251755759

Jéssica Andrade Vilas Boas: Universidade Federal de Itajubá, Itajubá, MG, Brasil. E-mail: jessica_eeparo@yahoo.com.br

Link para o currículo Lattes: http://lattes.cnpq.br/3451432930442475

Marcos Eduardo Cordeiro Bernardes: Universidade Federal do Sul da Bahia, Itabuna, BA, Brasil.

E-mail: marcos.bernardes@gmail.com

Link para o currículo Lattes: http://lattes.cnpq.br/8907565424580663

Maria Inês Nogueira Alvarenga: Universidade Federal de Itajubá, Itajubá, MG, Brasil.

E-mail: minesalvarenga@gmail.com

Link para o currículo Lattes: http://lattes.cnpq.br/1593126558438262

Data de submissão: 26 de outubro de 2015

Data de recebimento de correções: 01 de maio de 2016

Data do aceite: 01 de maio de 2016

Avaliado anonimamente 